\title{
Computational Analysis of a Chevron Nozzle Uniquely Tailored for Propulsion Airframe Aeroacoustics
}

\author{
Steven J. Massey* \\ Eagle Aeronautics, Inc., Hampton, VA 23669, USA \\ Alaa A. Elmiligui ${ }^{\dagger}$ \\ Analytical Services \& Materials Inc., Hampton, VA 23666, USA \\ Craig A. Hunter, Russell H. Thomas, and S. Paul Pao, \\ NASA Langley Research Center, Hampton, VA 23681, USA \\ Vinod G. Mengle" \\ The Boeing Company, Seattle, WA 98124, USA
}

\begin{abstract}
A computational flow field and predicted jet noise source analysis is presented for asymmetrical fan chevrons on a modern separate flow nozzle at take off conditions. The propulsion airframe aeroacoustic asymmetric fan nozzle is designed with an azimuthally varying chevron pattern with longer chevrons close to the pylon. A baseline round nozzle without chevrons and a reference nozzle with azimuthally uniform chevrons are also studied. The intent of the asymmetric fan chevron nozzle was to improve the noise reduction potential by creating a favorable propulsion airframe aeroacoustic interaction effect between the pylon and chevron nozzle. This favorable interaction and improved noise reduction was observed in model scale tests and flight test data and has been reported in other studies. The goal of this study was to identify the fundamental flow and noise source mechanisms. The flow simulation uses the asymptotically steady, compressible Reynoldsaveraged Navier-Stokes equations on a structured grid. Flow computations are performed using the parallel, multi-block, structured grid code PAB3D. Local noise sources were mapped and integrated computationally using the Jet3D code based upon the Lighthill Acoustic Analogy with anisotropic Reynolds stress modeling. In this study, trends of noise reduction were correctly predicted. Jet3D was also utilized to produce noise source maps that were then correlated to local flow features. The flow studies show that asymmetry of the longer fan chevrons near the pylon work to reduce the strength of the secondary flow induced by the pylon itself, such that the asymmetric merging of the fan and core shear layers is significantly delayed. The effect is to reduce the peak turbulence kinetic energy and shift it downstream, reducing overall noise production. This combined flow and noise prediction approach has yielded considerable understanding of the physics of a fan chevron nozzle designed to include propulsion airframe aeroacoustic interaction effects.
\end{abstract}

\section{Nomenclature}

Axi Axisymmetric fan and core nozzle configuration

bb Baseline nozzle configuration with pylon and without chevrons

$D \quad$ Core exit diameter

$\hat{k} \quad$ Mass averaged non-dimensional turbulence intensity, see equation (1)

$k \quad$ Turbulence kinetic energy per unit mass (TKE)

LAA Lighthill Acoustic Analogy

\footnotetext{
* Senior Research Scientist, s.j.massey@larc.nasa.gov, 13 West Mercury Blvd., Member AIAA

† Senior Scientist, 107 Research Dr., Member AIAA

$\ddagger$ Aerospace Engineer, Configuration Aerodynamics Branch, MS 499

$\S$ Senior Research Engineer, Aeroacoustics Branch, MS 166, Senior Member AIAA

๑Senior Research Engineer, Configuration Aerodynamics Branch, MS 499, Associate Fellow AIAA

${ }$ Engineer/Scientist, Acoustics and Fluid Mechanics, P.O. Box 3707, MC: 67-ML, Senior Member AIAA
} 
LSAF Boeing Low Speed Aeroacoustic Facility

OASPL Overall Sound Pressure Level

PAA Propulsion Airframe Aeroacoustics

QTD2 Quiet Technology Demonstrator 2

RANS Reynolds Averaged Navier-Stokes

RR Reference chevrons on core and fan with pylon

RT Reference chevrons on core and T-fan azimuthally varying fan chevrons with pylon

SPL Sound Pressure Level

T-fan PAA fan nozzle with azimuthally varying chevron design

$u, v, w$ Mean flow velocity components

Symbols

$\rho \quad$ Density

\section{Introduction}

$\mathrm{B}_{2}$ OEING, General Electric, Goodrich, ANA, and NASA partnered to form the Quiet Technology Demonstrator 2 (QTD2) flight test project that flew in 2005. Herkes et al. ${ }^{1}$ describes the background and overview of the QTD2 project. In brief, the QTD2 flight test project developed and demonstrated a variety of advanced acoustic measurement methods and noise reduction technology to produce new understanding of aircraft acoustics physics, to validate prediction methods and to validate and mature technology to flight test readiness. Noise reduction technology included inlet, fan and core nozzle, and landing gear concepts. The subject of this paper, as part of a series of papers, is one fan nozzle noise reduction concept known as the Propulsion Airframe Aeroacoustics (PAA) T-fan nozzle.

The objective of this PAA T-fan noise reduction nozzle was to take the highly effective chevron noise reduction approach and improve its noise reduction further by favorably incorporating the effects created when an exhaust nozzle is integrated with a pylon (strut) and wing. These pylon and wing effects are part of those effects created by the integration of propulsion and airframe and are described in general as Propulsion Airframe Aeroacoustics (PAA) effects.

The chevron nozzle has been the subject of intense research over the past decade because it can be very effective at jet noise reduction with minimal performance or weight impacts. For example, Janardan et al. ${ }^{2}$ describes some of the early model scale development results. As a result, chevron technology has advanced significantly and even entered commercial application in recent years. Chevrons appear as triangular trailing edge serrations. Even with their simple shape, there are many important parameters such as the immersion into the stream, relative velocities on either side of the chevron, and number of chevrons circumferentially, among others. The basic mechanism of the chevron is to create stream-wise vorticity that has an impact on the mixing of the jet and generally reduces the low frequency noise of the spectrum. Much recent research has focused on reducing a possible negative side effect of increasing immersion, that of increased high frequency noise. Chevron design is then a balance of reducing the low frequency while preventing high frequency increases.

A parallel area of research that was developing over roughly the same time frame has been to understand the PAA installation effects, including those of chevron nozzles. PAA effects that are relevant include how the chevron nozzle might interact with or be impacted by the presence or integration with the pylon, wing, and flaps. The possibility of this interaction also raised the potential to design favorably for this interaction and improve installed noise reduction. A number of studies were carried out that began to piece together an understanding of the effect of the pylon on jet noise as a necessary building block.

Bhat $^{3}$ studied the azimuthal effects of a pylon by testing a 1/20th scale model of a bypass ratio five separate flow nozzle to measure the effect of the pylon and bifurcator relative to the baseline axisymmetric nozzle. The effect of adding the bifurcator was found to add 1.0 EPNdB (at $\mathrm{M}=0.24$ ) relative to the baseline. With the pylon installed an azimuthal directivity was measured at about $2 \mathrm{EPNdB}$ at low power settings and 3.5 EPNdB at high power settings. No chevron nozzles were included in this study.

Martens ${ }^{4}$ did include a chevron core nozzle and a pylon in the acoustic results from the test of a bypass ratio five separate flow nozzle. The chevron core nozzle produced about a 2-3 EPNdB reduction compared to the baseline core nozzle for this 1/11th scale model of the CFM56-5B exhaust system. For both baseline and chevron nozzles, differences of 1-2 EPNdB were noticed for the two azimuthal angles tested corresponding to the sideline and the cutback conditions. 
An additional study measured the effect of a pylon on nozzles of bypass ratio five and eight and also including chevron nozzles. ${ }^{5}$ For the bypass ratio five configuration, the addition of the pylon reduced the noise by approximately $1 \mathrm{EPNdB}$ compared to the baseline case and there was little effect of azimuthal angle, not significantly above the level of repeatability. The core chevron produced a 1.8 EPNdB reduction compared to the baseline nozzle. Adding a pylon to the chevron core nozzle produces some reduction in the benefit of the core chevrons. The azimuthal directivity remains low at less than $0.5 \mathrm{EPNdB}$. For the bypass ratio eight configuration, the effect of adding a pylon to the baseline nozzle is to slightly increase the noise at higher cycle points. For the case with a core chevron, the pylon has little effect. The azimuthal angle effect was, however, very small in this case.

In general, these experimental studies indicated that there were clearly two PAA effects; 1) a sizable effect of the pylon itself (even without chevrons), which apparently depended on the specific design of the pylon and, 2) the orientation of the chevrons relative to the pylon.

These experimental results of Thomas and $\mathrm{Kinzie}^{5}$ have been used in the validation of the computational prediction capability of the mean flow field Massey et al. ${ }^{6}$ and the installed jet noise prediction capability of the JET3D ${ }^{7}$ code discussed by Hunter and Thomas. ${ }^{8}$ These computational studies also continued a series of analysis of the complex development of this asymmetric flow field and noise source distribution. Many detailed observations gave an increasing understanding of PAA effects. The primary flow expands into the wake of the pylon, increasing the mixing between the two streams and modifying the noise sources. The resulting plume cross-section is asymmetric with the bulk of the primary flow weighted toward the direction of the pylon.

To gain a better understanding of the basic pylon effect, without chevrons, Hunter et al. ${ }^{9}$ again studied the configurations of Thomas and Kinzie. ${ }^{5}$ This computational study resulted in an in-depth connection between the geometry and the resulting flow field and noise source changes with the addition of the pylon. In general, the effect of the pylon is to change the development of the primary and secondary streams downstream of a separate flow nozzle. Weak, large-scale secondary flows were identified that correlated with the re-distribution of the fan and core shear layer merging downstream. The secondary flows are fundamentally the result of the aerodynamic close-out of the pylon. The result is that the trajectory of the core stream and the fan stream is no longer co-axial and the shear layer merging and turbulence kinetic energy is non-symmetric azimuthally.

Furthermore, Elkoby ${ }^{10}$ reviewed PAA effects and analyzed the results between one recent static engine and flight test to quantify, with the available data and methods, PAA effects for a full-scale configuration including an interaction of the jet and wing and flap that was observed in the forward arc at lower frequencies. These results indicated the implications for jet-pylon effects relative to additional wing and flap interactions.

With the background of these studies, the opportunity developed to take the highly successful chevron noise reduction approach and incorporate PAA principles to improve the overall noise reduction by accounting for the nonsymmetric flow interactions that occur between the exhaust system, the engine strut, and the wing flow. Mengle et

al. ${ }^{11-13}$ documents the design and model scale studies of a series of azimuthally varying chevrons developed during the QTD2 partnership to validate the idea that a chevron nozzle can be designed with a unique azimuthal variation of the chevrons that will produce enhanced noise reduction in the fully installed configuration relative to the conventional azimuthally uniform chevron type. Mengle et al. ${ }^{1-13}$ reports that one chevron design, the PAA T-fan chevron with larger chevrons close to the strut, was the most successful from these studies and, as a result, it was selected for flight test on QTD2.

In this paper, a computational investigation is carried out using flow and noise predictions further developed from the previous series of studies. The objective is to propose an understanding of the connection between the uniquely tailored PAA T-fan design and the resulting flow development and noise source predictions relative to a uniform chevron design and baseline round nozzles. The result is a proposed theory for how the asymmetric PAA T-fan chevron interacts with the already asymmetric pylon effect to create the successful noise results already documented.

In addition to Mengle et al. ${ }^{11-13}$ and this paper, two more companion papers focus on the flight tests results of this nozzle together with a core chevron nozzle to determine the acoustic results under community noise conditions ${ }^{14}$ and then for shock-cell noise at cruise conditions. ${ }^{15}$

\section{Numerical Method}

Flow field computations are performed using the Reynolds-averaged Navier-Stokes code PAB3D ${ }^{16}$ with an added eddy viscosity dependence ${ }^{17}$ on total temperature gradient through the variation of the $C_{\mu}$ closure coefficient of the standard ${ }^{18}$ two equation $k-\varepsilon$ turbulence model. Viscous diffusion terms are modeled as uncoupled in the flow direction and fully coupled in the cross-flow direction and a three-factor scheme is used for the approximation of implicit terms. 
Noise source maps are computed with the Jet3 $\mathrm{D}^{7,8}$ code, which uses the CFD solution as input. Jet3D is based on a modern implementation of Lighthill's Acoustic Analogy (LAA) with anisotropic Reynolds stress modeling, and has been developed to handle complex three-dimensional turbulent flows and installed jet configurations. Jet3D SPL predictions for separate flow nozzles including an isolated pylon have been shown to be in good agreement with experimental noise measurements in the inlet arc up to $121^{\circ}$, beyond which low frequency SPL levels were under predicted due to the inherent limitations in the implementation of the LAA scheme used in Jet3D. ${ }^{8}$ In this study, Jet3D is utilized to produce noise source maps which are correlated to the local flow features. This approach was recently successfully applied to separate flow nozzles with an isolated pylon by Hunter et al. ${ }^{9}$

The computational domain extends six core diameters upstream from the fan exit, 30 downstream and eight radially. Transitions from boundary to shear layer grids are smoothed to aid convergence. The average value of the law of the wall coordinate, $y^{+}$, of the first cell center is less than one on all viscous surfaces. Grid sequencing is used to accelerate convergence by sequentially solving $1 / 4,1 / 2$ and the full grid in each of the three computational directions. The typical iteration count for 3-D grids at each grid level is 10,000 . The flow residual normally drops by four to five orders of magnitude.

Average grid sizes in this study are approximately 30 million cells, compared to similar grids of half that size in previous studies. ${ }^{5,6,9,19}$ The additional resolution is aimed at better resolving the complex flow initiated by both fan and core chevrons. All surfaces are gridded and run as viscous with the exception of the very small tip region of the plug and the very thin nozzle trailing edges.

A typical run for the fully converged solution at the fine grid level on a 31 million cell grid required 149 wall clock hours on 42 Pentium 4 nodes, with the solver running in parallel at a speed on the order of one micro-second per iteration per cell.

\section{Results and Discussion}

In this study, the mean flow field and noise are computed on four nozzle configurations of increasing geometric complexity, as shown in Figure 1. All configurations were run at the model scale and take off conditions used in the NASA/Boeing LSAF acoustic tests. ${ }^{11}$ The baseline nozzle is nominally a bypass ratio of eight. The wind tunnel is at Mach 0.30 for the take off nozzle condition. The fan nozzle pressure ratio is 1.735 and the core nozzle pressure ratio is 1.622 , with a total temperature ratio between fan and core flows of 2.513 . The first nozzle is purely axisymmetric and was constructed computationally from the baseline (bb) nozzle lines. This axisymmetric nozzle was not part of the NASA/Boeing LSAF experiments and is part of this computational study for comparison with the bb nozzle in order to demonstrate the effect of the pylon on the cross-sectional secondary flow field. The bb nozzle is the configuration with the baseline core and fan nozzles with the pylon. The RR configuration has reference uniform azimuthally chevrons on both the core and fan nozzles. The RT configuration has the same reference chevrons on the core with the PAA T-fan chevron nozzle with its uniquely tailored azimuthally varying chevron pattern. More details of these configurations can be found in Mengle et al. ${ }^{11}$ Noise was computed for the axisymmetric case, but experimental data from LSAF only exists for the latter three nozzle configurations, bb, RR and RT. Furthermore, the axisymmetric case was run at the same exit conditions of the other nozzles, but effectively has a larger fan area without the pylon and so would have higher thrust. This is important to take into account, but for the purposes of this study it should not limit the conclusions regarding trends and fundamental flow and noise source mechanisms.

The approach that will be followed in this discussion is to start with the final noise prediction results and work backwards to increasingly fundamental quantities to form an unbroken chain linking noise all the way back to geometry. With this link established, further physics guided geometry changes can be made to further optimize PAA enhanced nozzles in future studies.

Noise prediction results from Jet3D are compared to LSAF acoustic data ${ }^{11}$ for an observer located on a $68.1 D$ radius from the fan nozzle exit at an inlet angle of $88.5^{\circ}$ and an azimuthal angle of $180^{\circ}$, which is directly below the pylon. This location for the predictions is $6^{\circ}$ azimuthally different from the actual microphone location, the reader is refered to Mengle et al. ${ }^{11}$ for details of the experimental setup. SPL predictions are in very good agreement with experimental SPL data throughout the frequency range for the bb, RR and RT configurations (see Figure 2). The discrepancy in the low frequency data (below $400 \mathrm{~Hz}$ ) is known to be caused by tunnel noise. ${ }^{11}$ Predictions for the RR configuration were slightly higher than data in the low frequency range, and slightly lower in the high frequency range, with the change over at about $10 \mathrm{kHz}$. Despite small discrepancies in the RR configuration, Jet3D did correctly capture the general trend between what are complex three-dimensional configurations with asymmetric nozzles and a pylon and with hot separate flows. Jet3D correctly predicts at this observer location that bb is the loudest, RR in the middle, and RT the quietest. Though no noise data exists for the hypothetical axisymmetric nozzle, its SPL prediction is presented as a reference only to show the general effect of the pylon. 
An OASPL noise source histogram is computed by sorting the Jet3D noise sources as computed from the Lighthill Acoustic Analogy (LAA) into $0.25 \mathrm{D}$ wide bins and plotting against their axial location (see Figure 3). The value of the histogram is to show the contribution to the noise at the $88.5^{\circ}$ observer location, in this case, from the entire jet length. The noise trend shown here between bb, RR, and RT configurations is in line with the SPL results, with the RT nozzle showing noticeably less noise in the $4 \leq x / D \leq 10$ range and slightly more noise from $10 \leq x / D \leq 20$. The Axi nozzle shows large differences from the bb case with a pylon, with higher noise for $x / D \leq 5$, much less from $5 \leq x / D \leq 12$ and much greater for $x / D \geq 12$. This is consistent with the absence of the pylon effect. As a typical round separate flow nozzle case, the Axi case has a more even distribution of noise sources as a function of axial distance with a less dramatic peak noise that occurs around $x / D$ of 13 as compared to a peak around $x / D$ of 8 for the configurations that include the pylon.

In previous studies ${ }^{5,6,9}$ of a similar seperate flow nozzle and pylon, an understanding of the basic pylon effect was developed. The pylon effect causes an initial increase in noise due to an earlier mixing of core and fan shear layers and an azimuthal redistribution of the noise producing shear layers. Depending on the magnitude of the mixing, the bypass ratio and the shape of the pylon, it can be beneficial or harmful to the overall noise. In Figure 3, we see the fundamental difference between the Axi case and the bb case as consistent with previous understanding. However, the new question is to understand the difference between the RR and RT cases, both of which have the same pylon but different fan chevrons.

A fundamental bridge from RANS CFD to noise prediction is seen in the similarity of plots of mass averaged non-dimensional turbulence intensity $\hat{k}$ in Figure 4 and the noise source histogram Figure $3 . \hat{k}$ is defined by Eq. 1 .

$$
\hat{k}=\frac{\int_{A} \sqrt{\frac{k}{u^{2}+v^{2}+w^{2}}} \rho u d A}{\int_{A} \rho u d A}
$$

Of note in the connection, is the nearly identical correspondence of axial location of relative noise levels of all the cases, to relative turbulence intensity levels. While the full LAA is needed to make quantitative predictions, $\hat{k}$ is sufficient (at least for this family of nozzles) to show relative noise levels verses axial location. However, the histogram does show this more directly and accurately particularly for $x / D \leq 5$. To amplify the small differences in $\hat{k}$, a percent difference relative to the baseline bb case is shown in Figure 5 which confirms previous observations.

Jet3D noise source maps in Figures 6-9 show the overall noise per unit volume for each cell in the CFD simulation as predicted by the Lighthill Acoustic Analogy (LAA) implementation in Jet3D. Figure 6 shows the Axi configuration noise map as a round jet reference. This noise map shows a basic acoustic asymmetry due to the observer being off to one side of the jet. This is a characteristic of the implementation of LAA in Jet3D, which results in spatial phasing of noise sources due to anisotropic Reynolds stress modeling (the effect is not present for isotropic turbulence), see Hunter $^{7}$ and Hunter and Thomas. ${ }^{8}$ Figure 7 shows the basic pylon effect of the bb case previously discussed where noise sources move upstream asymmetrically into the wake of the pylon. Comparing Figures 8 and 9 shows that the peak noise sources, both in the symmetry plane and the cross planes, are lower for RT than RR.

As with integrated turbulence (Figures 4 and 5), the symmetry plane turbulence kinetic energy, Figure 10, shows one view of the outstanding result of the basic pylon effect. The core and fan stream merging is accelerated and is asymmetric relative to the axisymmetric case because the core and fan streams have effectively different trajectories caused by the close out of the pylon. That early merger creates increased turbulence in the wake region of the pylon relative to the axisymmetric case. In Figure 11, turbulence kinetic energy contours are shown with superimposed crossflow streamlines. The plots are shown as split screens with the axisymmetric configuration on the left half of Figure 10a and the bb configuration on the right half of Figure 10a, for example. Even at $x / D$ of 3 , the presence of the pylon has a dramatic effect of creating a relative trajectory between the core and fan streams as shown in Figure 10a. Figure 10b shows the two chevron configurations, RR and RT, in split screen. Moving downstream to $x / D$ of 6 and 15 (Figures 10c and e) begins to indicate just how the secondary flow setup by the aerodynamic close out of the pylon is related to the redistribution of the fan and core shear layers and the resulting turbulence kinetic energy. Figures 10d and $\mathrm{f}$ begin to show the differences between the RR and RT configurations. Here the significant difference between TKE due to the junction of the fan and core shear layers can be seen. Also visible is the larger amount of TKE in the Axi case verses all others at $x / D=15$ (see Figure 11e). The downward displacement of the fan flow due to the pylon is also visible. However, Figure 10 shows that the fan flow from RT has not displaced down as much as for RR or bb.

As we progress further along the linkage from geometry to flow and noise we come to the axial component of vorticity. The crossflow velocity and the resulting vorticity is what moves and redistributes shear layers and the shear layers produce the turbulence that ultimately results in noise. The axial vorticity color contours are shown in Figure 12. The crossflow streamlines are again shown superimposed, as they are in several of the cross plots, in order to demonstrate the linkage of these key secondary flows to the various flow quantities being computed. The 
aerodynamic close out of this pylon is seen to generate three pairs of counter rotating vortices similar to the pylon effect from previous studies, two of which are of similar strength with the same orientation, and a much weaker third. Note, only one member of each pair is shown since all computations were done on half symmetry grids. While the upper vortex is simply due to the close out of the pylon, the lower strong vortex is contributed to by the interaction of the pylon close out with the plug close out and the core and fan shear flows. Finally, the weak fan vortex is due to the pylon interaction with the fan shear layer.

At this point it is important to emphasize an aspect of this complex flow that is evident throughout the figures being shown. There are three major effects at work in these cases, the pylon effect, the chevron effect, and then the asymmetric T-fan chevron effect. The key to understanding the physics of the RT nozzle lies in understanding the interactions between all of these effects. In Figure 12b, the stream-wise axial vorticity of the individual chevrons is evident and it is important to emphasize that vorticity from the individual chevrons is on a smaller scale than the larger scale vorticity set up by the pylon or, in the case of the T-fan, an interaction between the asymmetry of the T-fan chevrons and the pylon effect. In other words, the localized axial vorticity of the chevrons has its contribution to mixing and noise reduction that has been documented in many previous studies, but as is evident here, it is actually embedded within the larger scale vorticity of the pylon. And so as can be seen in RR and RT cases, the smaller scale vorticity generated by chevrons is seen to merge quickly within the larger scale vorticity of the pylon effect. Comparing the RR case (the left side of Figure 12d) with the basic pylon, bb (the right side of Figure 12c) shows the azimuthally uniform chevrons of the RR case have not changed the large scale vorticity of the pylon effect much. In essence, there has been a superposition of the azimuthally uniform chevron effect with the pylon effect. The conclusion is very different when comparing the RR and RT configurations in Figure 12d. Here the large scale vorticity in the core and fan streams is noticeably weaker in the RT case than in the RR case. The asymmetry of the T-fan must be counteracting the vorticity of the pylon effect and weakening, but not eliminating, the vorticity set up by the pylon close-out effect.

The pylon introduces a vertical geometric asymmetry, so it is natural to look at the vertical velocity component for differences among the configurations. It is also natural that a well designed PAA nozzle reflect a favorable vertical asymmetry in response to the pylon. In Figure 13, the vertical velocity component on the symmetry plane for each configuration is shown, with the Axi configuration having 1/5 the contour range to increase contrast. In all cases, the non-uniformity inside the nozzles are due to a slight change in the nozzle curvature at approximately $x / D=-2.5$. A single black contour line denotes zero vertical velocity and can be seen at $y / D=0$ as expected for most of the Axi configuration. For the pylon cases, the symmetry plane shows the core stream moving up while the fan stream moves down. While the bb and RR configurations are very similar, RT shows reduced levels of vertical velocity. However, this is not representative of the whole jet. To get a better understanding of the three dimensional aspects, the vertical velocity in the jet crossflow planes are shown in Figure 14. Focusing on the $x / D=6$ crossflow plane (Figure 14c) on the left, shows the axisymmetric crossflow streamlines and corresponding vertical velocity component typical of the entrainment of the Axi case. On the right side of Figure 14c, the pylon effect is more clear in the context of previous plots. Again, the aerodynamic close out of the pylon has several effects that make up the basic pylon effect. The bottom of the pylon, the shelf, creates a Coanda-like effect and draws the core flow up into the wake of the pylon. This is seen by the positive vertical velocity in Figure 14c near the axis. This upward move of the core flow creates a downward move by the fan flow as it fills in underneath the displaced core flow, which is evident in the negative vertical velocity between $z / D$ of 0 and 1 in the vicinity of the fan flow. The shear from these velocities in the vertical direction are related to the large scale axial vorticity. Figure 14d shows the reduced vertical velocity levels of the RT case compared to RR which is again consistent with the reduced large scale axial vorticity and secondary flow.

Axial velocity is plotted in Figures 15 and 16 on the symmetry and crossflow planes, respectively, to show the effect of secondary flows on the main flow and to give scaling to the secondary flow, which is seen to be as much as two orders of magnitude smaller. Finally, total temperature is plotted on the symmetry and crossflow planes in Figures 17 and 18, respectively. Total temperature indicates the general path of the fan and core flows as well as the result of their overall mixing. The length of the potential core is about the same for the bb and RR cases and about half a core diameter longer for the RT case, which indicates that for these nozzles the secondary flow effects are more important to noise then overall mixing. In these plots, the pylon cases all have cooler cores at $x / D=15$ and the relative position of the fan stream can again be seen to be affected primarily by the pylon effect. Of note in the total temperature crossflows is Figure 18f, which shows how the fan and core flows of the RT configuration have not moved down as much as for the RR configuration. This represents an overall measured result of the flow mechanisms detailed above that are different for the asymmetric RT nozzle compared to RR and bb. Again, the asymmetry of the PAA T-fan nozzle counteracts the basic pylon effect resulting in reduced secondary large scale vorticities (different from the stream-wise vorticity of the chevrons themselves) and reduced vertical velocities that result in the RT flow moving down (in this coordinate system) less than the RR or bb nozzle flows. This also results, as the previous plots have 
shown, in a slower merging of the fan and core shear layers, resulting in the reduced noise of the RT. This observation of how the RT nozzle reduces the secondary flow created by the pylon, but does not eliminate it, ties back to the noise histogram. Note in Figure 3 that the histogram of RT is in between, in effect, the Axi case and the bb and RR cases. There is noise reduction from the chevrons themselves, but RT has moderated the pylon effect to a more optimum level with reduced noise overall compared to RR. This connection tightens the linkage between geometry and predicted flow and noise sources and the experimental validation.

A final overall quantitative measure of the jet deflection due to the interaction of the pylon and chevrons can be seen by computing the centroid of the mass weighted average of total temperature at each axial location as shown in Figure 19. Because of the high bypass ratio, the fan flow dominates the average, so while the core tends to move up, the whole of the jet moves down, and again, the RT moves down the least.

\section{Concluding Remarks}

A computational flow field and noise prediction analysis was performed on a modern separate flow nozzle with complex three dimensional configurations from a pylon, reference azimuthally uniform chevrons and a final configuration including a PAA T-fan nozzle with azimuthally varying chevrons. The intent of this PAA T-fan chevron was to improve the noise reduction compared to standard uniform chevrons by incorporating principles from propulsion airframe aeroacoustic interactions. This intent was demonstrated at model scale and in flight as part of the Quiet Technology Demonstrator 2 flight test project. The result of this in depth computational study is to develop the linkage between the geometric features, the flow field, and the noise source distributions and to propose an understanding of the fundamental working principle of the PAA T-fan chevron. Simply, as is the case in propulsion airframe aeroacoustic interactions, multiple simultaneous phenomena are present in such a complex flow. The pylon effect on a baseline nozzle without chevrons creates large scale secondary vortices that displace the overall jet downward relative to the pylon and create a relative trajectory between the core and fan streams resulting in an accelerated merging of the core with the fan in the wake of the pylon. This accelerated merging increases turbulence kinetic energy in the wake of the pylon and moves peak noise sources upstream relative to the axisymmetric nozzle without a pylon. The addition of the azimuthally uniform chevrons imposes a classic chevron effect with its relatively small scale stream-wise vorticity. In general, this essentially symmetric chevron effect is superimposed on the otherwise asymmetric pylon effect and the two do not counteract each other significantly. In contrast, the PAA fan chevron with its asymmetric fan chevron does have an interaction with the basic pylon effect, the result being that the secondary flows set up by the pylon are mitigated and reduced in strength but, importantly, the pylon effect is not destroyed. The reduced pylon effect then creates a more mild merging of the fan and core shear layers moving the peak turbulence in the pylon wake farther downstream resulting in reduced overall noise.

The key result of the PAA T-fan chevron then is a more favorable propulsion airframe interaction with the effect of the pylon together producing an overall better distribution of noise sources. This new understanding has come from a very careful and consistent use of the combined flow and noise diagnostic tools of this study. This new level of PAA understanding now opens the possibility to provide analysis of why other PAA azimuthally varying chevron designs perform better or worse. It also opens the possibilities for further improved nozzle and pylon designs based on propulsion airframe aeroacoustic principles particularly to design nozzle and pylons in combination rather than designing a nozzle to work better with a particular pylon. And finally, when considering the expansion of the application of these PAA computational tools and analysis method to the full configuration and not just the nozzle and

pylon, the possibilities now exist to analyze and design the full configuration of nozzle, pylon, and flap system for favorable PAA effect interactions including all the parameters important to practical applications.

\section{Acknowledgments}

The authors would like to acknowledge the very successful collaboration with many colleagues at Boeing that contributed to the successful development and testing of the PAA T-fan nozzle at model scale and in flight during the QTD2 project. Many of these are listed as authors on other PAA T-fan related papers and also include other Boeing colleagues, notably Dr. Belur Shivashankara, Dr. Rob Stoker, Mr. Ron Olsen, and Mr. David Reed and the whole LSAF staff and QTD2 flight test staff. At NASA, the authors gratefully acknowledge the support of the Geolab staff in preparing grids, the Quiet Aircraft Technology Project management, Dr. Charlotte Whitfield, Aeroacoustics Branch Manager, and Mr. Larry Leavitt, Configuration Aerodynamics Branch Manager. 


\section{References}

${ }^{1}$ Herkes, W., Olsen, R., and Uellenburg, S., "The Quiet Technology Demonstrator Program: Flight Validation of Noise Reduction Concepts," AIAA Paper 2006-2720, May 2006.

${ }^{2}$ Janardan, B. A., Hoff, G. E., Barter, J. W., Martens, S., Gliebe, P. R., Mengle, V., and Dalton, W. N., "AST Critical Propulsion and Noise Reduction Technologies for Future Commercial Subsonic Engines, Separate-Flow Exhaust System Noise Reduction Concept Evaluation," NASA CR 2000-210039, Dec. 2000.

${ }^{3}$ Bhat, T. R. S., "Experimental Study of Acoustic Characteristics of Jets from Dual Flow Nozzles," AIAA Paper 2001-2183, May 2001.

${ }^{4}$ Martens, S., "Jet Noise Reduction Technology Development at GE Aircraft Engines," ICAS Paper 842, Sept. 2002.

${ }^{5}$ Thomas, R. H. and Kinzie, K. W., "Jet-Pylon Interaction of High Bypass Ratio Separate Flow Nozzle Configurations,” AIAA Paper 20042827, May 2004

${ }^{6}$ Massey, S. J., Thomas, R. H., Abdol-Hamid, K. S., and Elmilgui, A. A., "Computational and Experimental Flow Field Analysis of Separate Flow Chevron Nozzles and Pylon Interaction," AIAA Paper 2003-3212, May 2003.

${ }^{7}$ Hunter, C. A., An Approximate Jet Noise Prediction Method based on Reynolds-Averaged Navier-Stokes Computational Fluid Dynamics Simulation, D.Sc. dissertation, The George Washington University, Virginia, Jan. 2002.

${ }^{8}$ Hunter, C. A. and Thomas, R. H., "Development of a Jet Noise Prediction Method for Installed Jet Configurations," AIAA Paper 2003-3169, May 2003.

${ }^{9}$ Hunter, C. A., Thomas, R. H., Abdol-Hamid, K. S., Pao, S. P., Elmiligui, A. A., and Massey, S. J., "Computational Analysis of the Flow and Acoustic Effects of Jet-Pylon Interaction,” AIAA Paper 2005-3083, May 2005.

${ }^{10}$ Elkoby, R., "Full-Scale Propulsion Airframe Aeroacoustics Investigation,” AIAA Paper 2005-2807, May 2005.

${ }^{11}$ Mengle, V., Elkoby, R., Brusniak, L., and Thomas, R., "Reducing Propulsion Airframe Aeroacoustic Interactions with Uniquely Tailored Chevrons: Part 1. Isolated Nozzles," AIAA Paper 2006-2467, May 2006.

${ }^{12}$ Mengle, V., Elkoby, R., Brusniak, L., and Thomas, R., "Reducing Propulsion Airframe Aeroacoustic Interactions with Uniquely Tailored Chevrons: Part 2. Installed Nozzles," AIAA Paper 2006-2434, May 2006.

${ }^{13}$ Mengle, V., Elkoby, R., Brusniak, L., and Thomas, R., "Reducing Propulsion Airframe Aeroacoustic Interactions with Uniquely Tailored Chevrons: Part 3. Jet-Flap Interaction,” AIAA Paper 2006-2435, May 2006.

${ }^{14}$ Nesbitt, E., Mengle, V., Czech, M., Callendar, B., and Thomas, R., "Flight Test Results for Uniquely Tailored Propulsion Airframe Aeroacoustic Chevrons: Community Noise," AIAA Paper 2006-2438, May 2006.

${ }^{15}$ Mengle, V., Ganz, U., Nesbitt, E., Bultemeier, E., and Thomas, R., "Flight Test Results for Uniquely Tailored Propulsion Airframe Aeroacoustic Chevrons: Shockcell Noise," AIAA Paper 2006-2439, May 2006.

${ }^{16}$ Abdol-Hamid, K. S., "Development of Three-Dimensional Code for the Analysis of Jet Mixing Problem," NASA CR 4200, 1988.

${ }^{17}$ Abdol-Hamid, K. S., Pao, S. P., Massey, S. J., and Elmiligui, A. A., "Temperature Corrected Turbulence Model for High Temperature Jet Flow," ASME Journal of Fluids Engineering, Vol. 126, No. 5, 2004, pp. 844-850.

${ }^{18}$ Jones, W. P. and Launder, B. E., "The Prediction of Laminarization with a Two-Equation Model of Turbulence," Int. J. Heat Mass Transf., Vol. 15, No. 2, 1972, pp. 301-314.

${ }^{19}$ Thomas, R. H., Kinzie, K. W., and Pao, S. P., “Computational Analysis of a Pylon-Chevron Core Nozzle Interaction,” AIAA Paper 20012185, May 2001. 


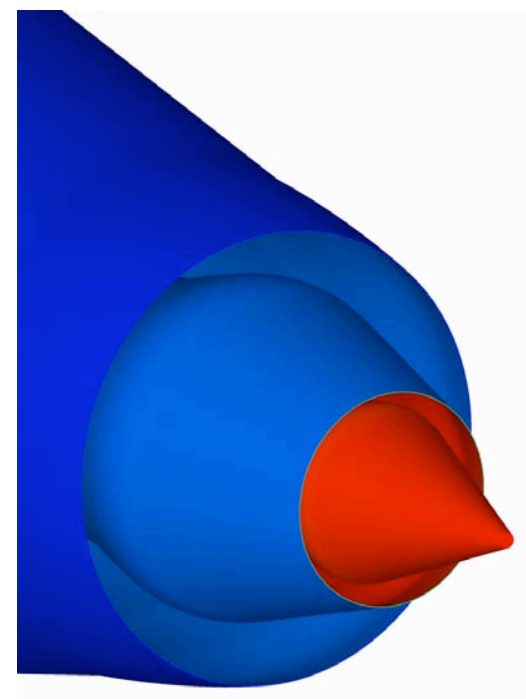

(a) Axisymmetric (Axi)

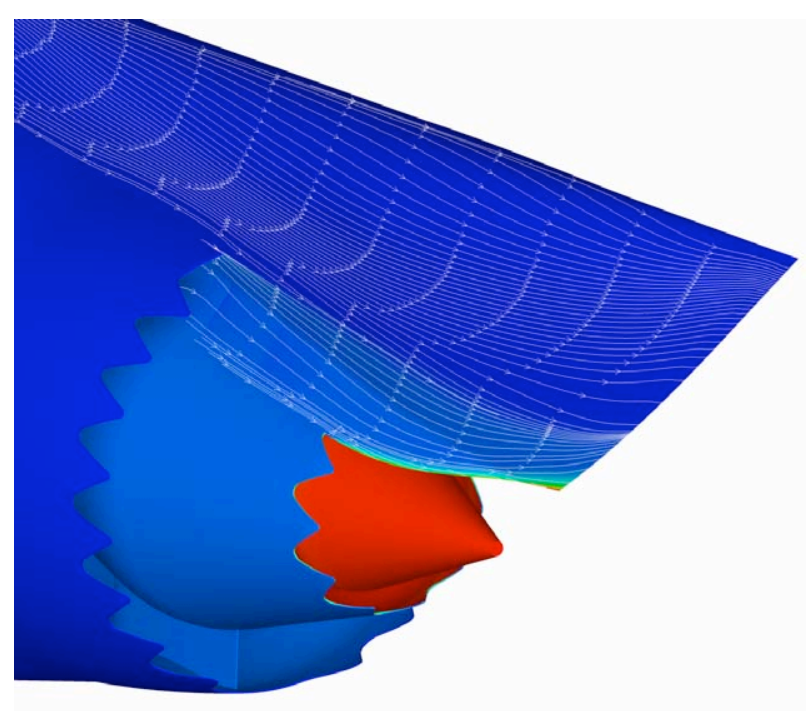

(c) Reference Chevron (RR)

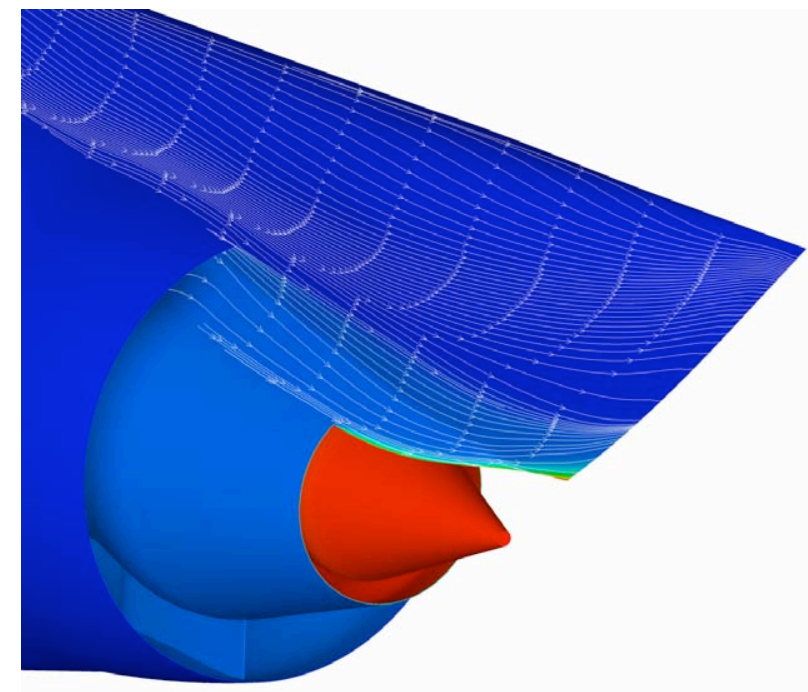

(b) Baseline (bb)

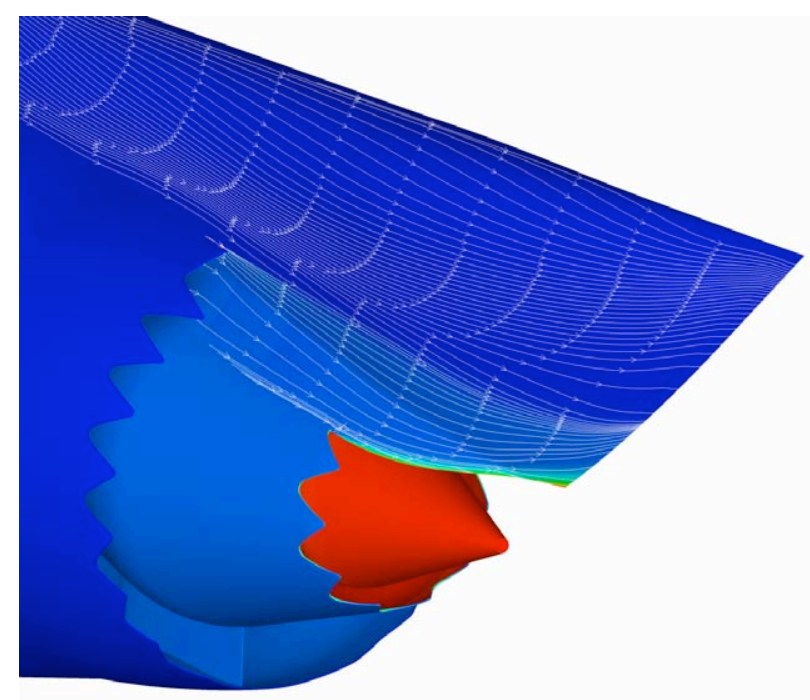

(d) PAA Chevrons (RT)

Figure 1. CFD model surfaces colored by temperature with pylon oil flow streamlines. 


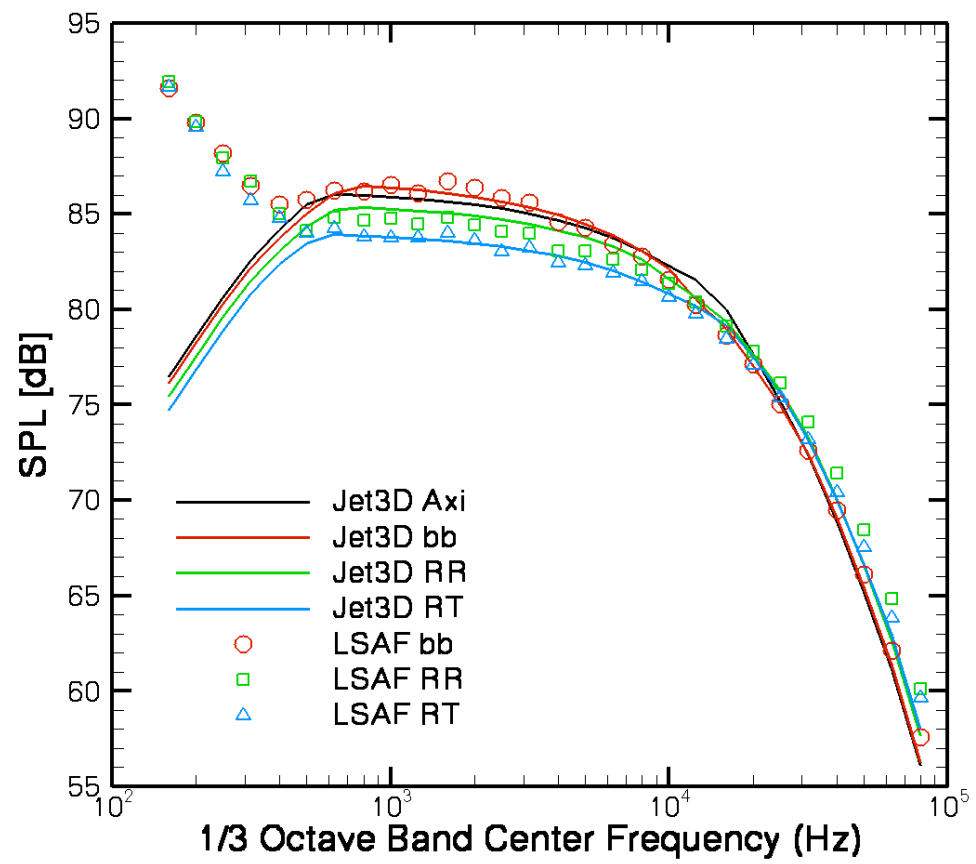

Figure 2. SPL predictions from Jet3D compared with LSAF data. Observer located on a 68.1D radius from the fan nozzle exit at an inlet angle of $88.5^{\circ}$ and an azimuthal angle of $180^{\circ}$.

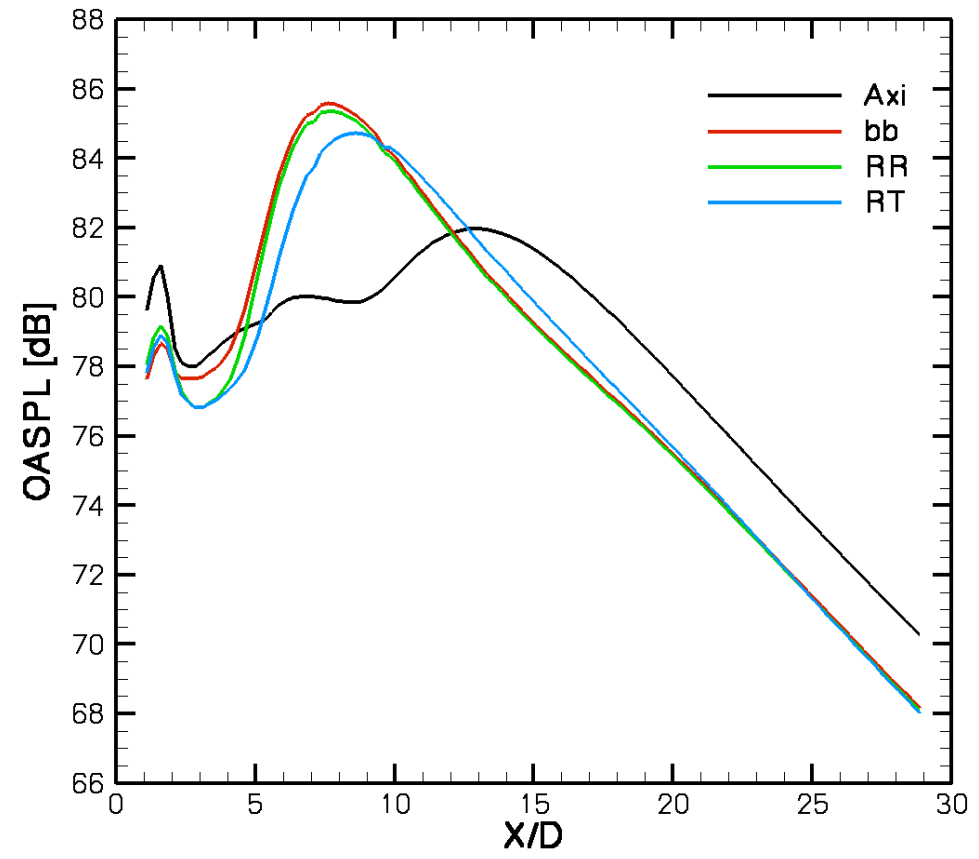

Figure 3. OASPL noise source histogram for an observer located on a 68.1D radius from the fan nozzle exit at an inlet angle of 88.5 ${ }^{\circ}$ and an azimuthal angle of $180^{\circ}$. Noise sources have been sorted into $0.25 \mathrm{D}$ wide bins and plotted by axial location, starting from the core nozzle exit and moving downstream. 


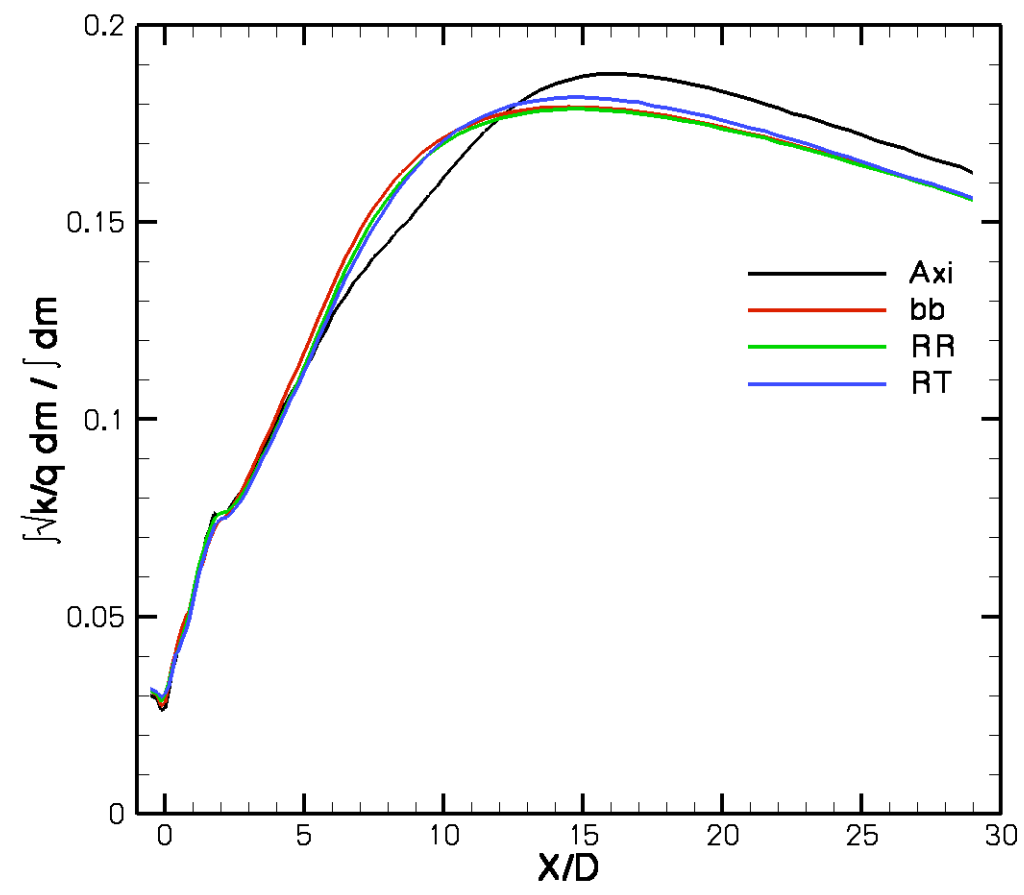

Figure 4. Mass averaged, non-dimensional turbulence intensity.

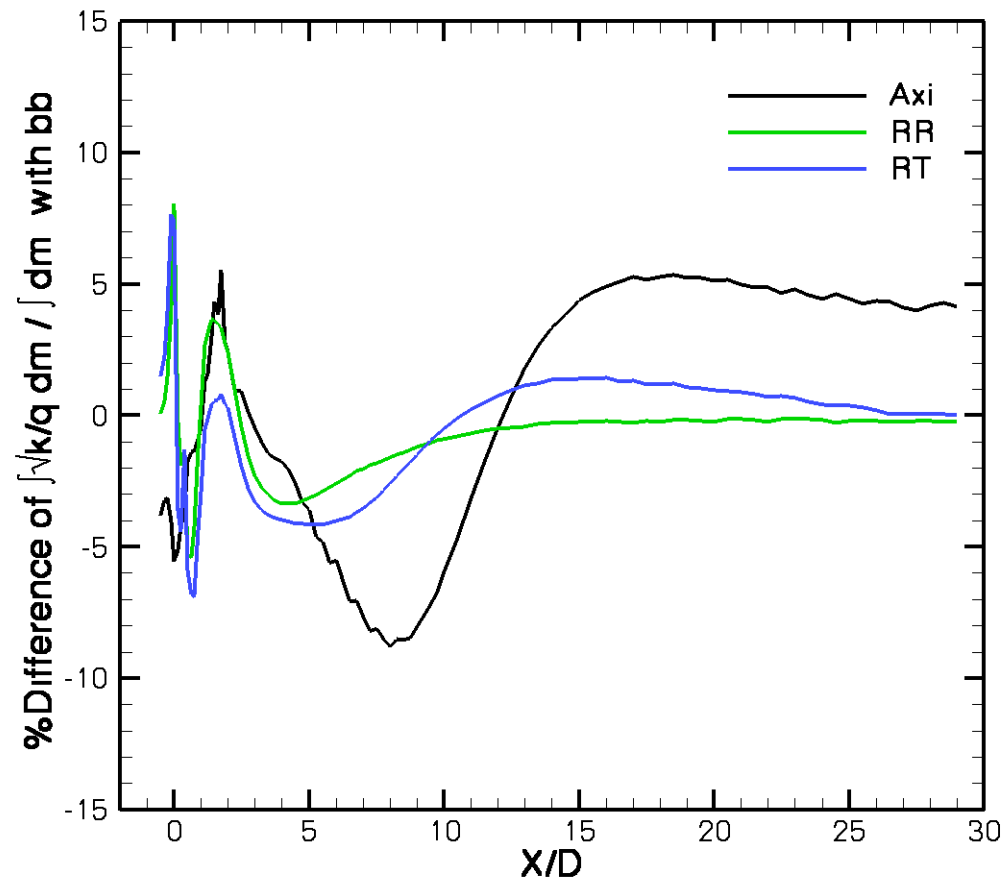

Figure 5. Percent difference relative to configuration bb of mass averaged, non-dimensional turbulence intensity. 

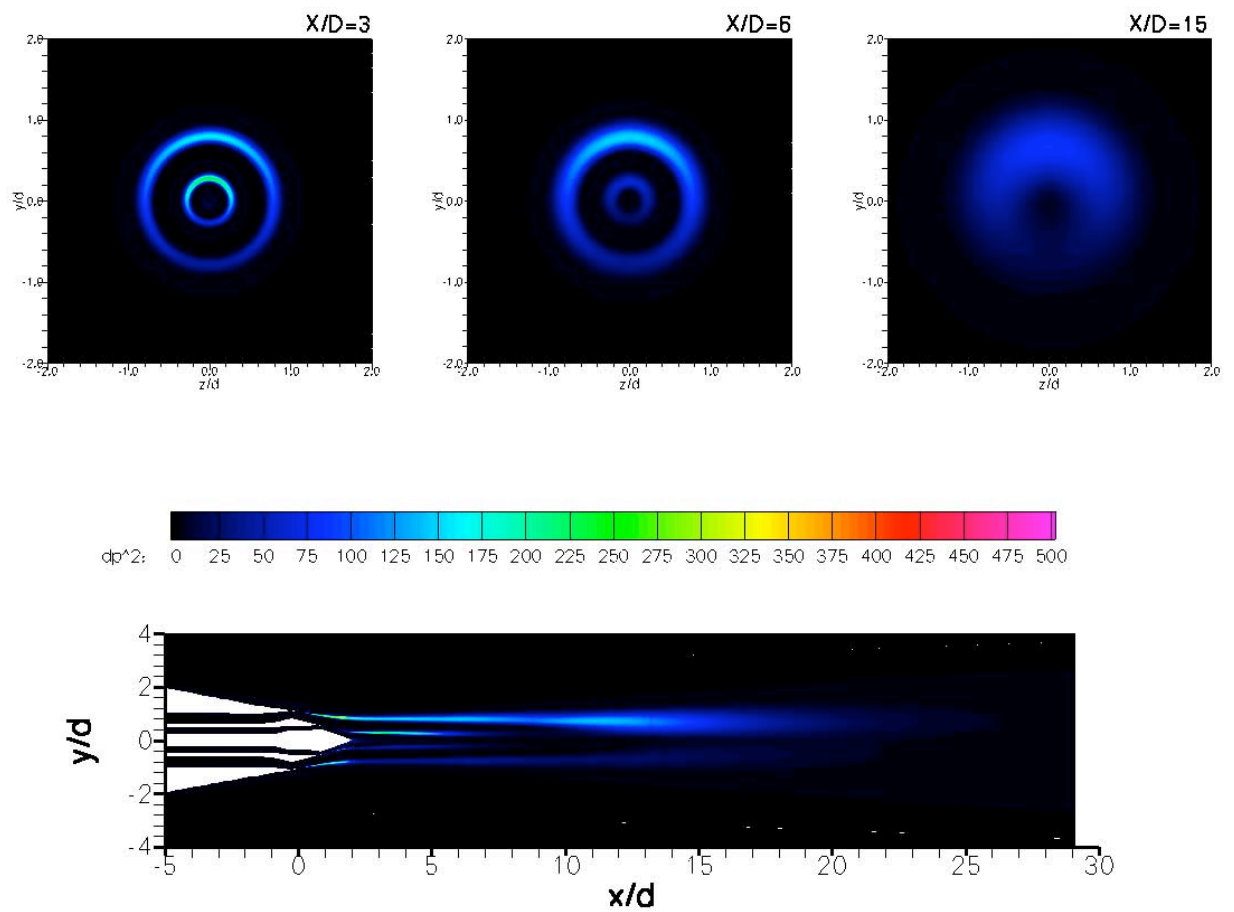

Figure 6. Axisymmetric Configuration: OASPL noise source maps computed from Jet3D for an observer located on a 68.1D radius from the fan nozzle exit at an inlet angle of $88.5^{\circ}$ and an azimuthal angle of $180^{\circ}$. Contours show mean-square acoustic pressure per unit volume, with units of $\left(\mathrm{N} / \mathrm{m}^{2}\right)^{2} / \mathrm{m}^{3}$
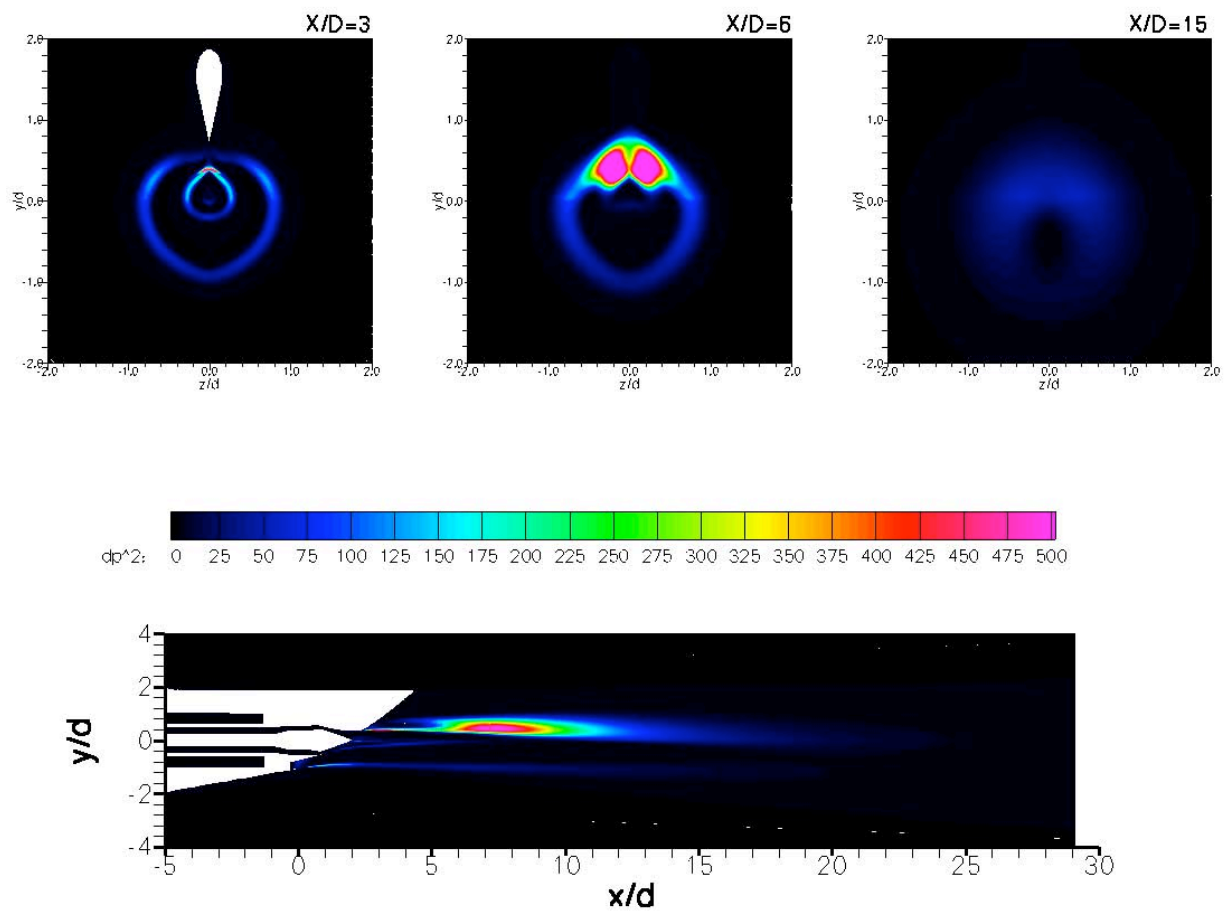

Figure 7. Baseline (bb): OASPL noise source maps computed from Jet3D for an observer located on a 68.1D radius from the fan nozzle exit at an inlet angle of $88.5^{\circ}$ and an azimuthal angle of $180^{\circ}$. Contours show mean-square acoustic pressure per unit volume, with units of $\left(\mathrm{N} / \mathbf{m}^{2}\right)^{2} / \mathbf{m}^{3}$ 

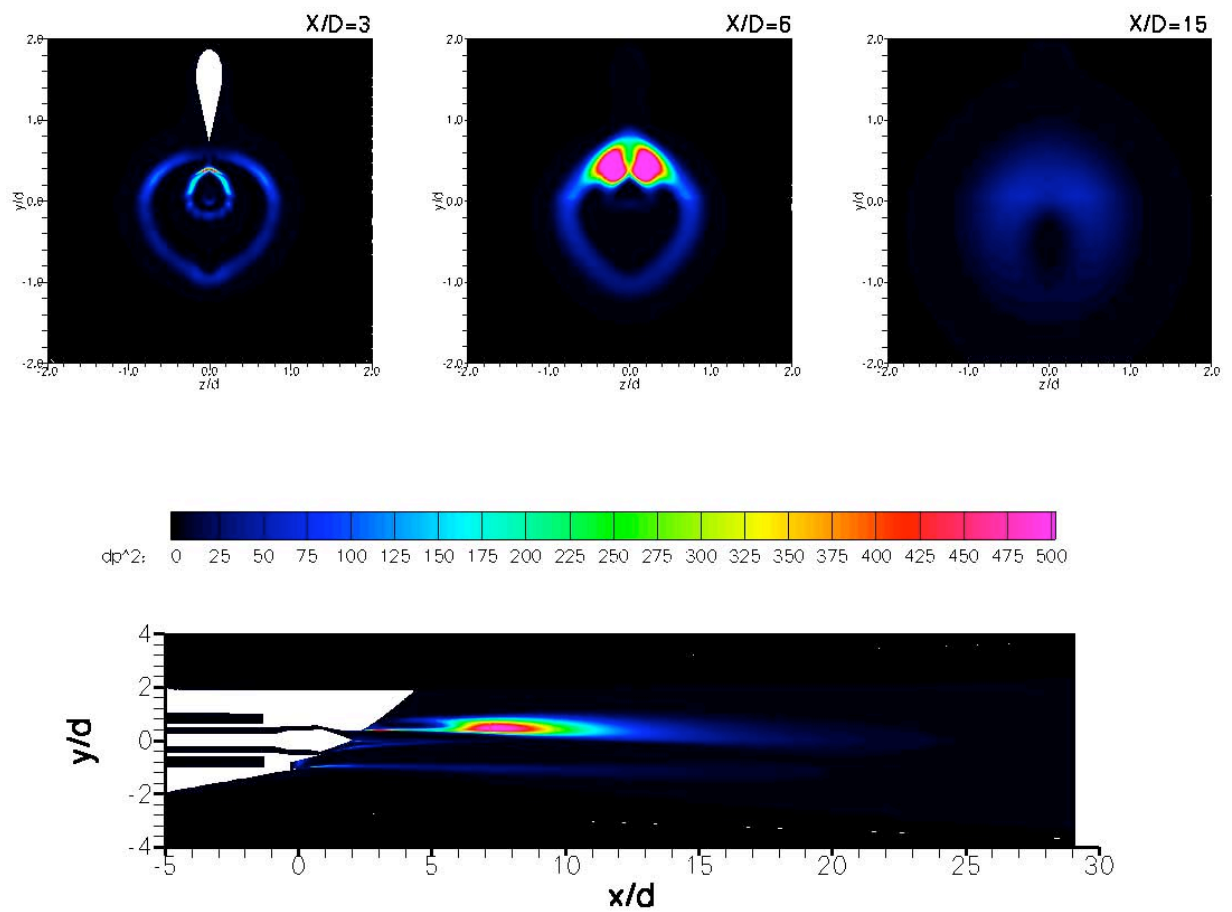

Figure 8. Reference Chevron (RR) : OASPL noise source maps computed from Jet3D for an observer located on a 68.1D radius from the fan nozzle exit at an inlet angle of $88.5^{\circ}$ and an azimuthal angle of $180^{\circ}$. Contours show mean-square acoustic pressure per unit volume, with units of $\left(\mathrm{N} / \mathrm{m}^{2}\right)^{2} / \mathrm{m}^{3}$.
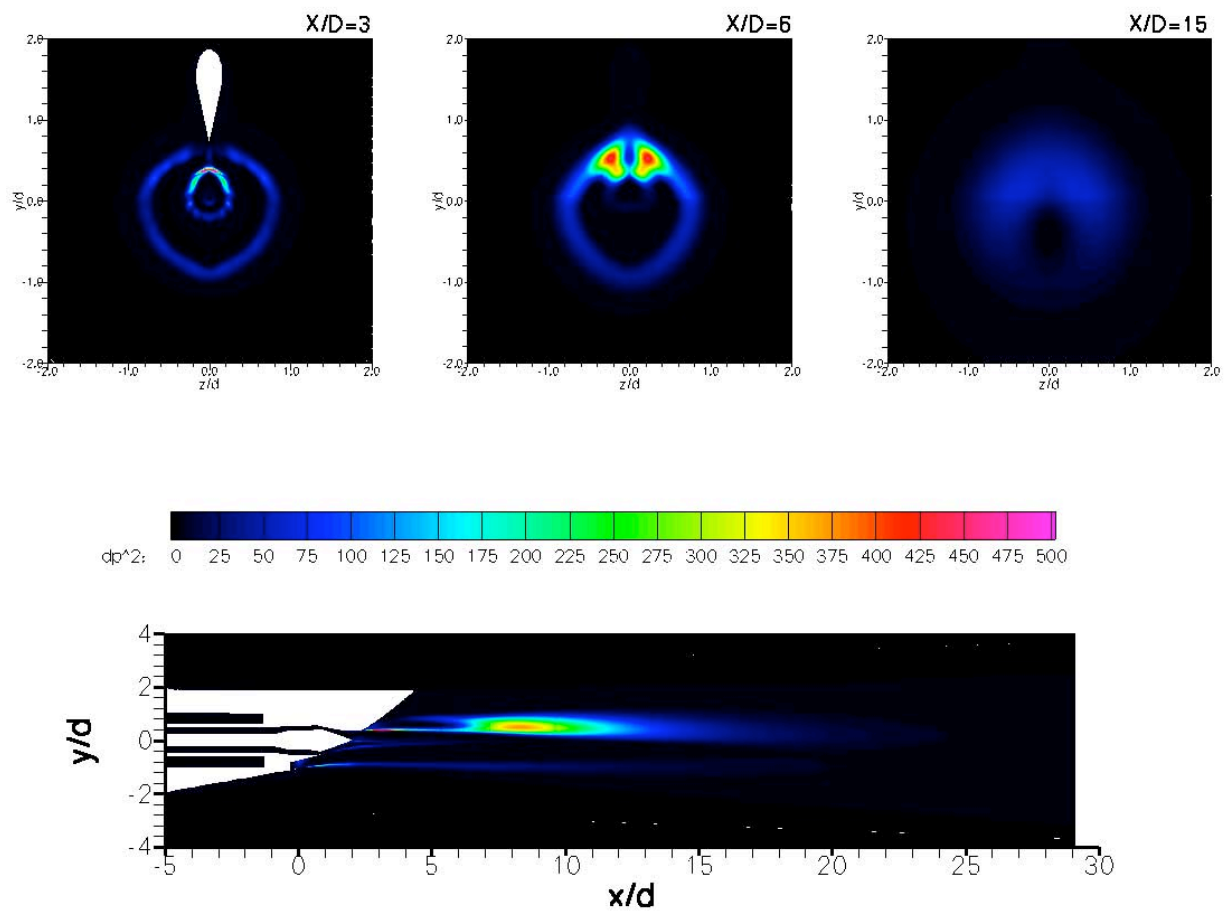

Figure 9. PAA Chevrons (RT): OASPL noise source maps computed from Jet3D for an observer located on a 68.1D radius from the fan nozzle exit at an inlet angle of $88.5^{\circ}$ and an azimuthal angle of $180^{\circ}$. Contours show mean-square acoustic pressure per unit volume, with units of $\left(\mathrm{N} / \mathrm{m}^{2}\right)^{2} / \mathrm{m}^{3}$. 


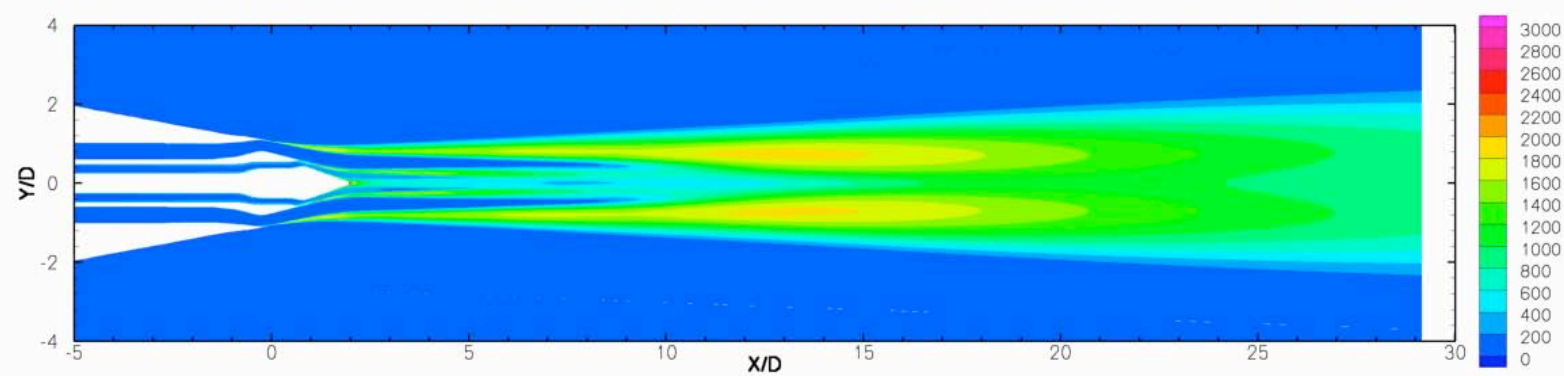

(a) Axisymmetric

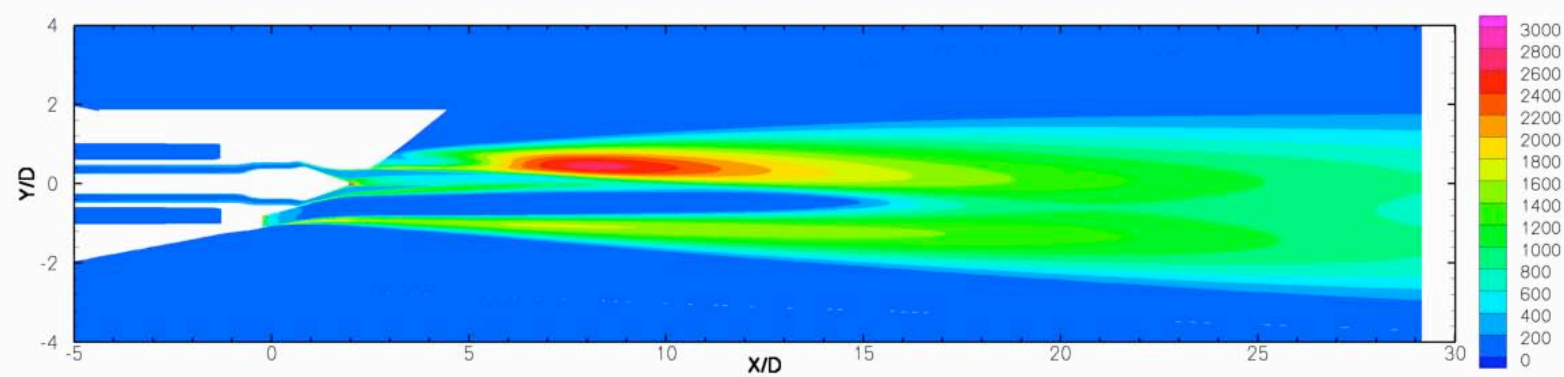

(b) Baseline (bb)

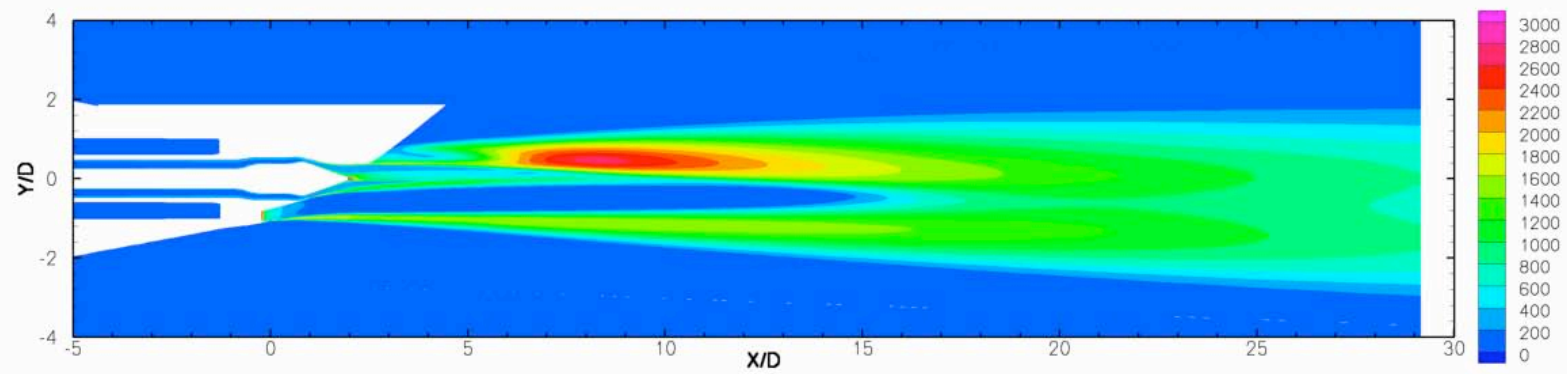

(c) Reference Chevron (RR)

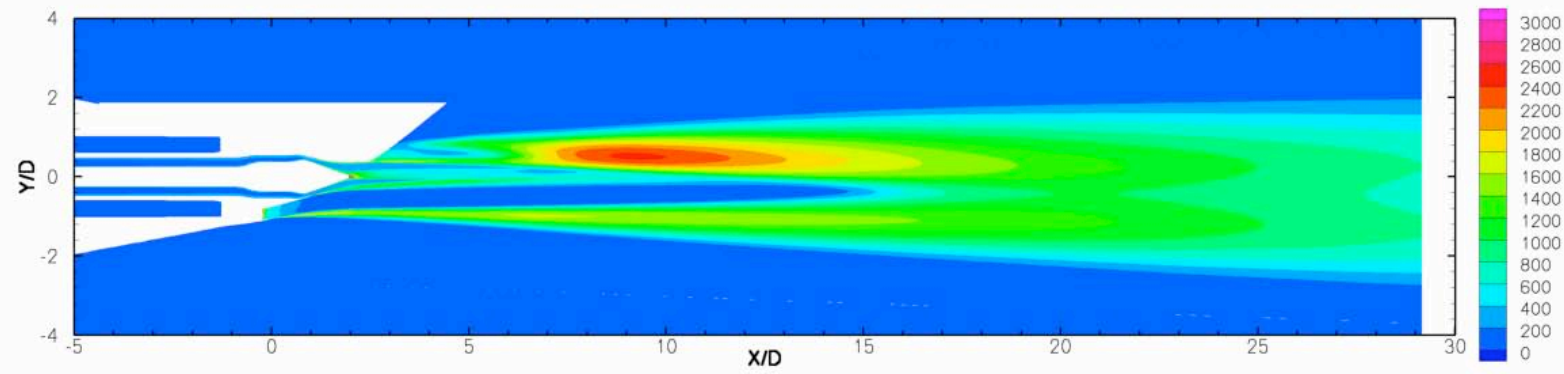

(d) PAA Chevrons (RT)

Figure 10. Turbulence kinetic energy per unit mass $\left[\mathrm{m}^{2} / \mathrm{s}^{2}\right]$ on symmetry planes. 


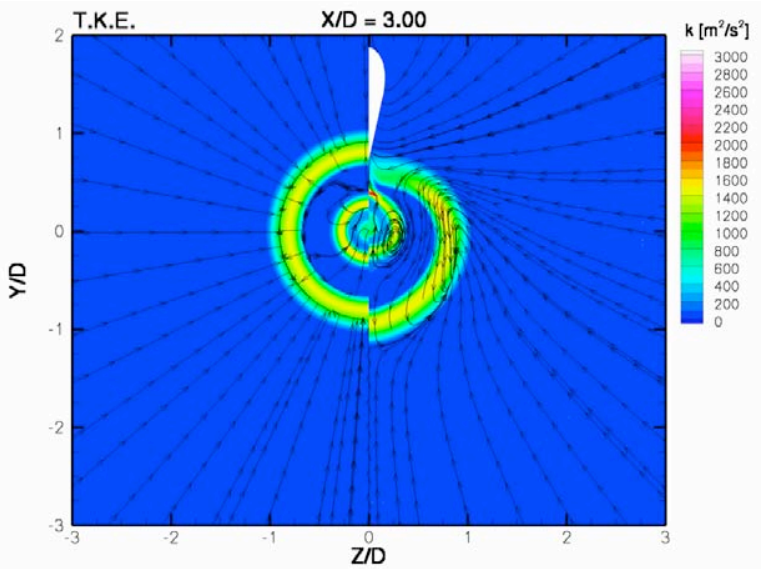

(a) $x / D=3$ : Axisymmetric left, Baseline (bb) right

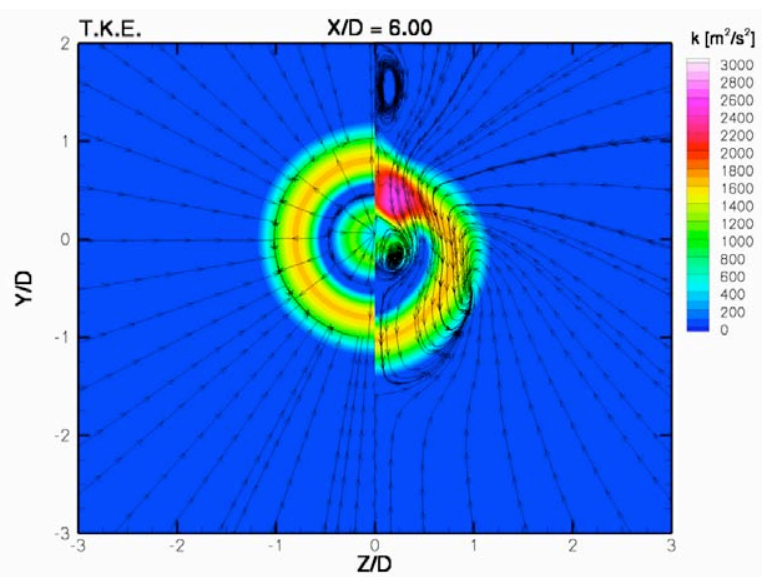

(c) $x / D=6$ : Axisymmetric left, Baseline (bb) right

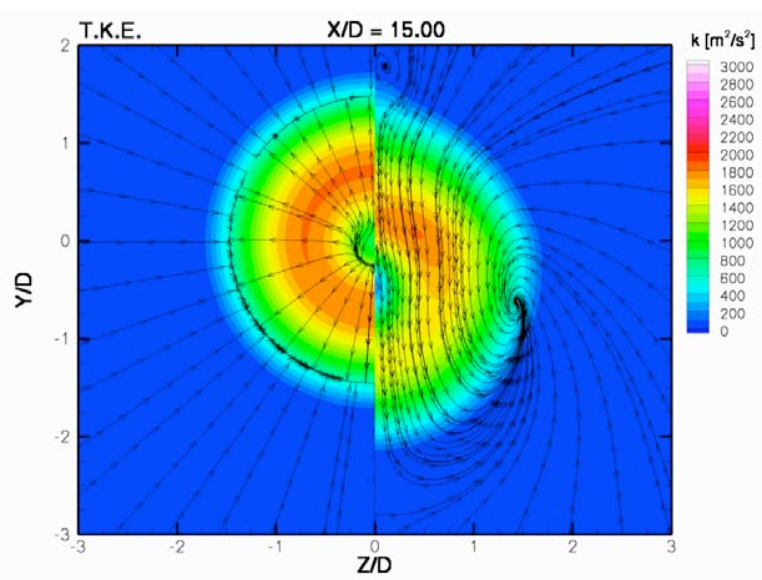

(e) $x / D=15:$ Axisymmetric left, Baseline (bb) right

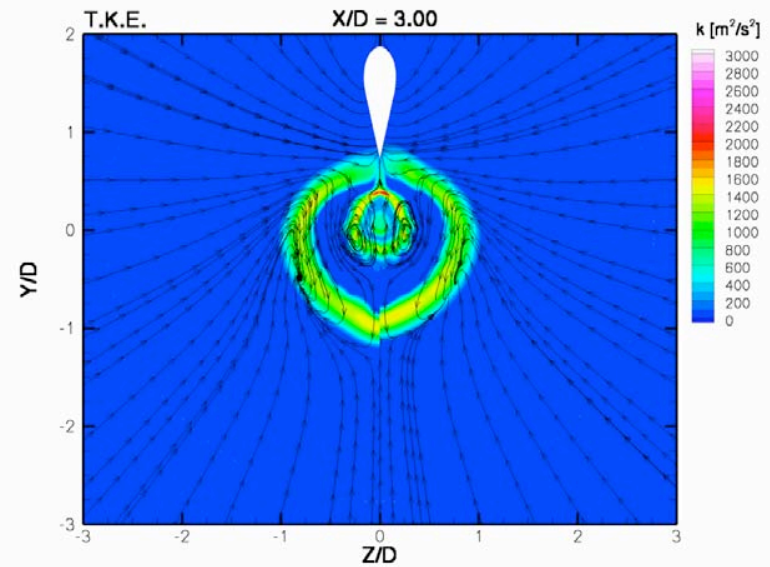

(b) $x / D=3$ : Reference Chevron (RR) left, PAA Chevrons (RT) right

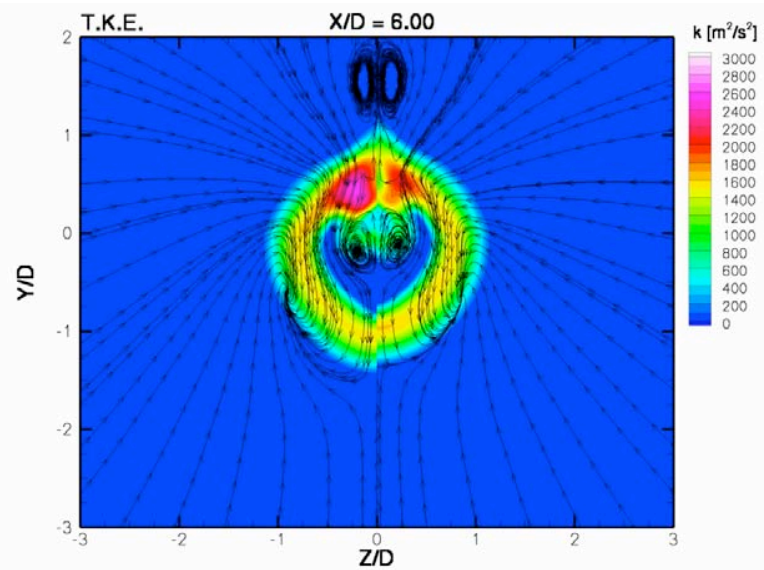

(d) $x / D=6$ : Reference Chevron (RR) left, PAA Chevrons (RT) right

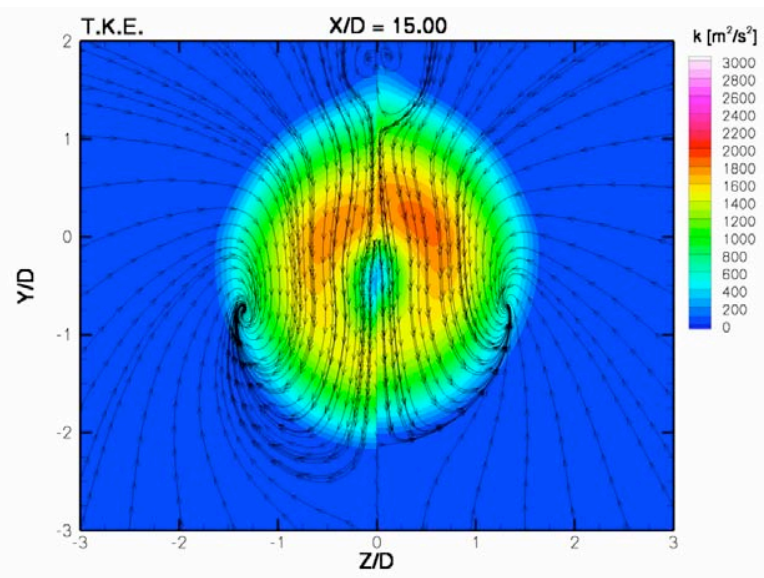

(f) $x / D=15$ : Reference Chevron (RR) left, PAA Chevrons (RT) right

Figure 11. Turbulence kinetic energy per unit mass $\left[\mathbf{m}^{2} / \mathbf{s}^{2}\right]$ with crossflow streamlines at $x / D=3,6,15$ 


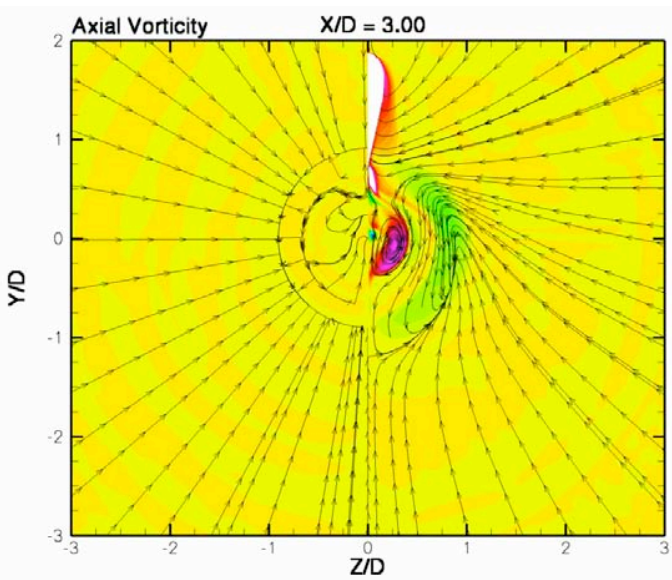

(a) $x / D=3$ : Axisymmetric left, Baseline (bb) right

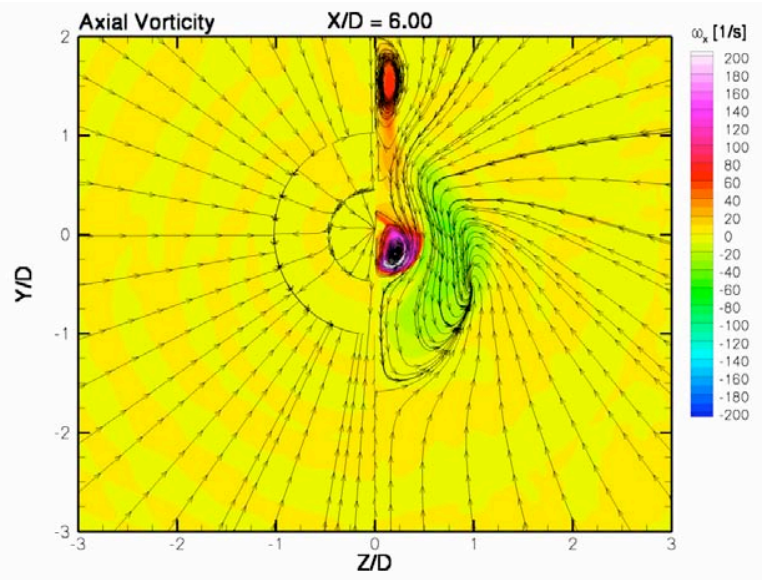

(c) $x / D=6$ : Axisymmetric left, Baseline (bb) right

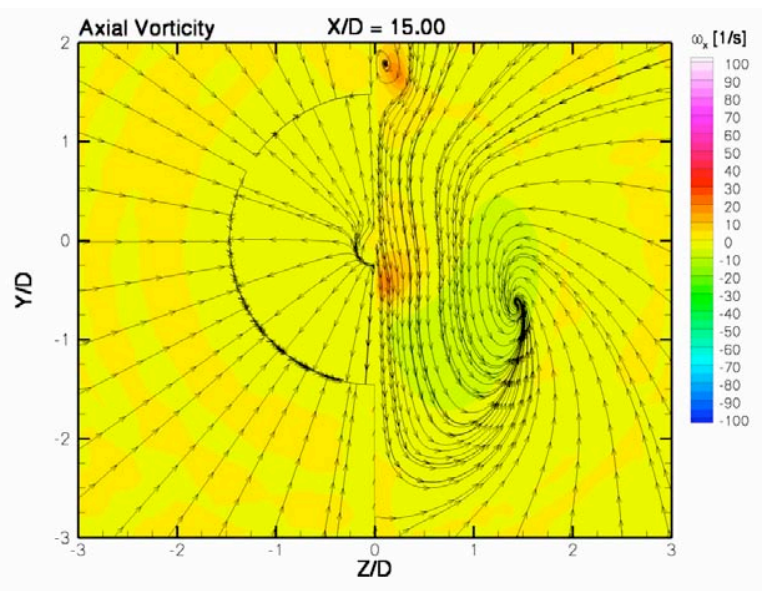

(e) $x / D=15$ : Axisymmetric left, Baseline (bb) right

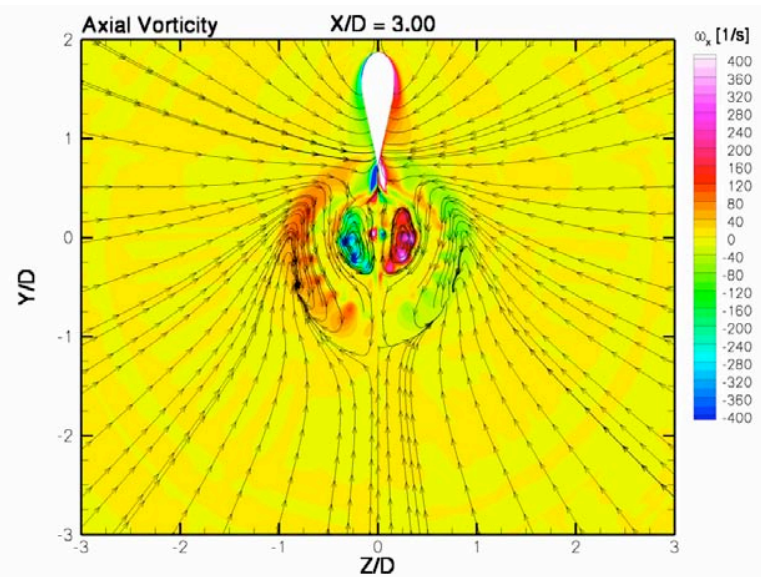

(b) $x / D=3$ : Reference Chevron (RR) left, PAA Chevrons (RT) right

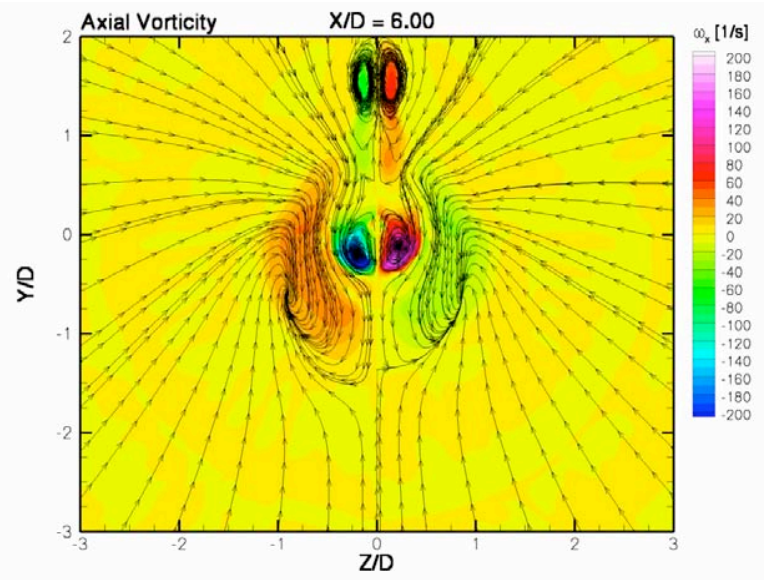

(d) $x / D=6$ : Reference Chevron (RR) left, PAA Chevrons (RT) right

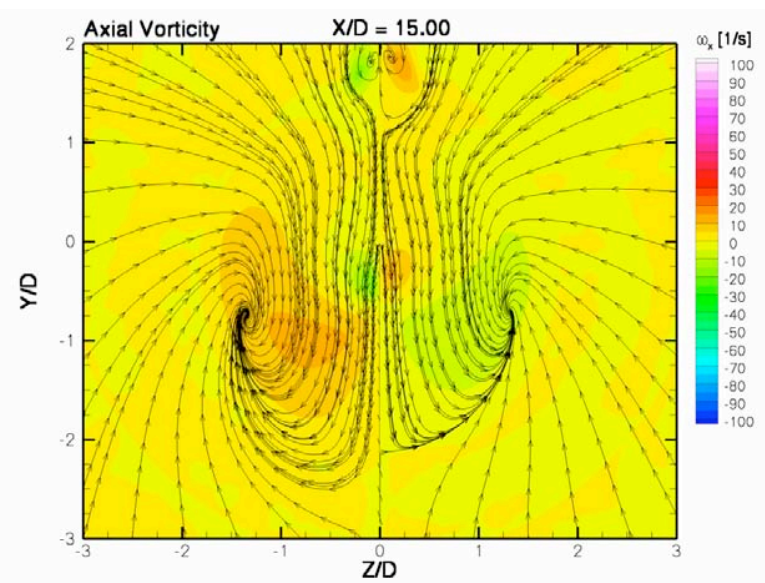

(f) $x / D=15:$ Reference Chevron (RR) left, PAA Chevrons (RT) right

Figure 12. Axial vorticity component $[\mathbf{1} / \mathbf{s}]$ with crossflow streamlines at $x / D=3,6,15$ 


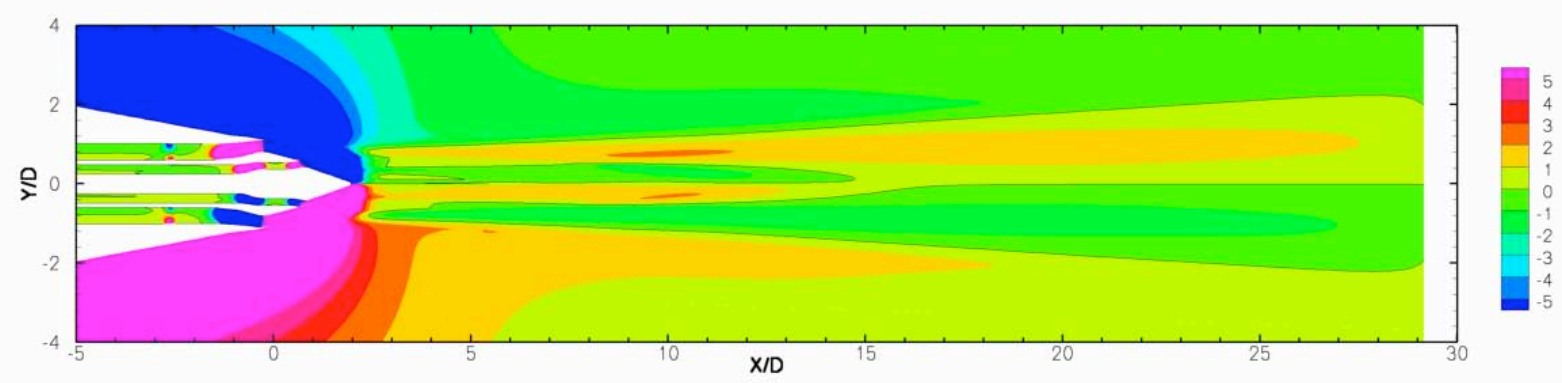

(a) Axisymmetric

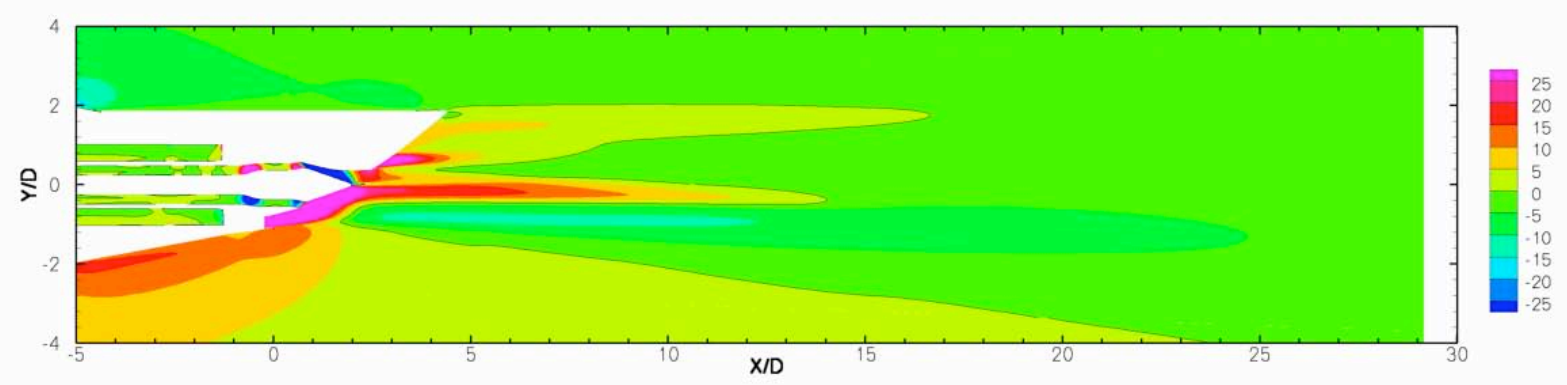

(b) Baseline (bb)

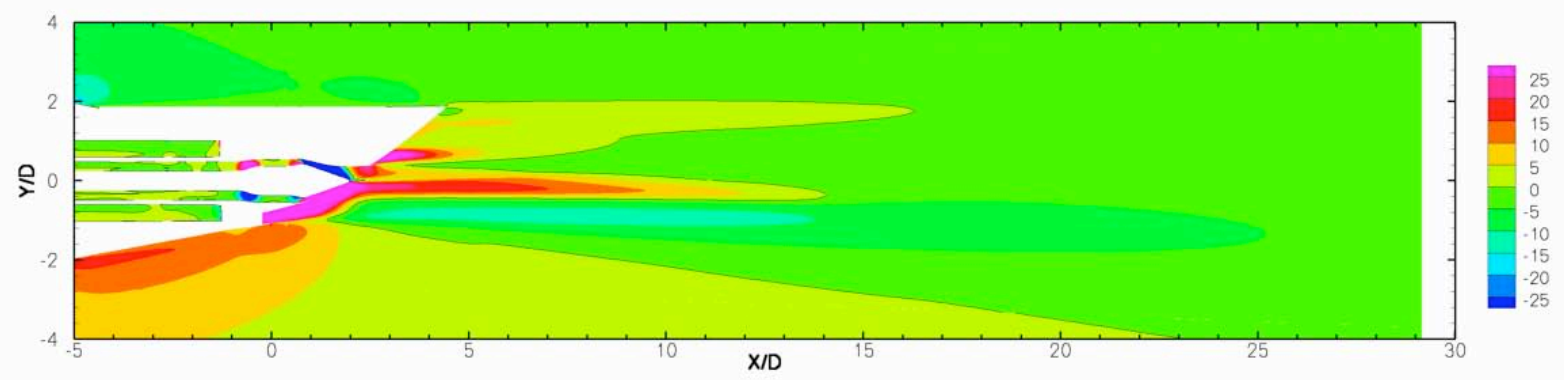

(c) Reference Chevron (RR)

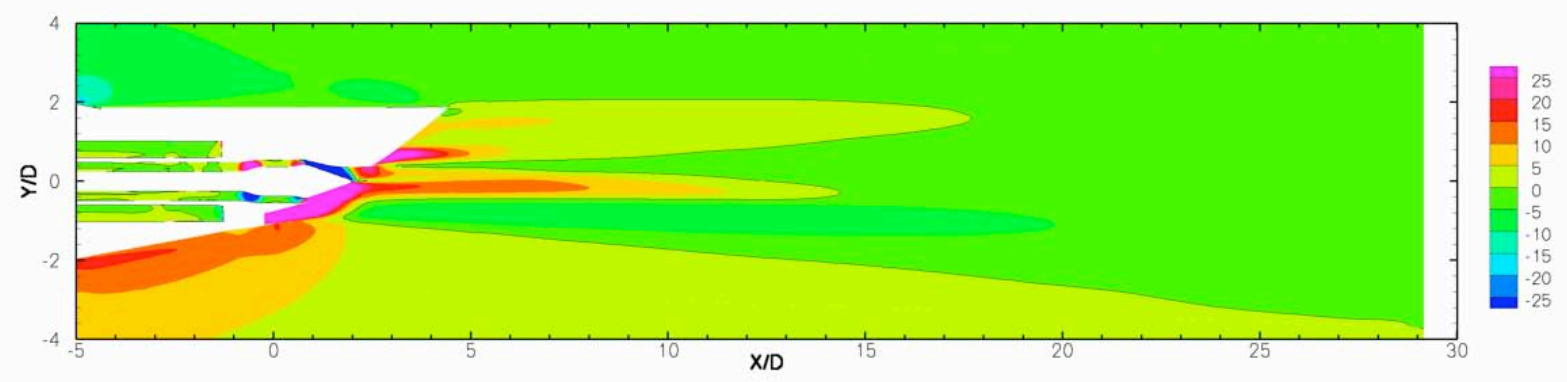

(d) PAA Chevrons (RT)

Figure 13. Vertical velocity component, $v[\mathrm{~m} / \mathrm{s}]$ on symmetry planes. Axisymmetric contour range is plotted at $1 / 5$ of the pylon cases. 


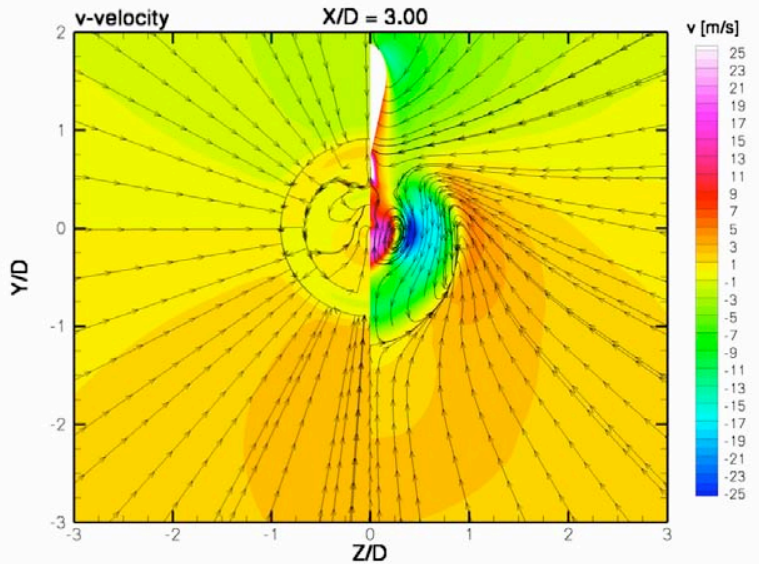

(a) $x / D=3$ : Axisymmetric left, Baseline (bb) right

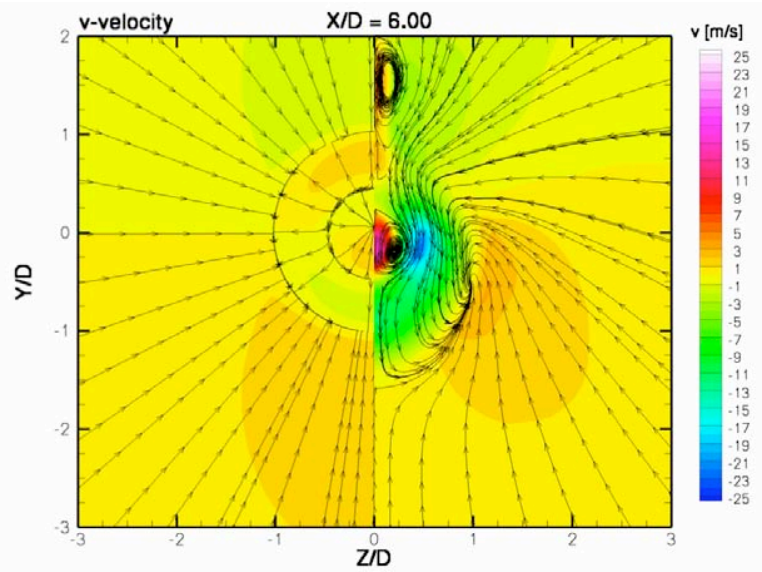

(c) $x / D=6$ : Axisymmetric left, Baseline (bb) right

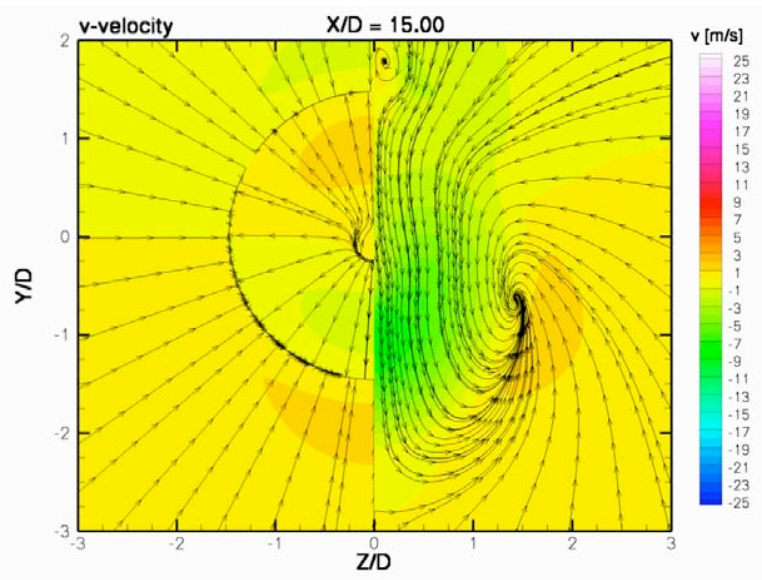

(e) $x / D=15$ : Axisymmetric left, Baseline (bb) right

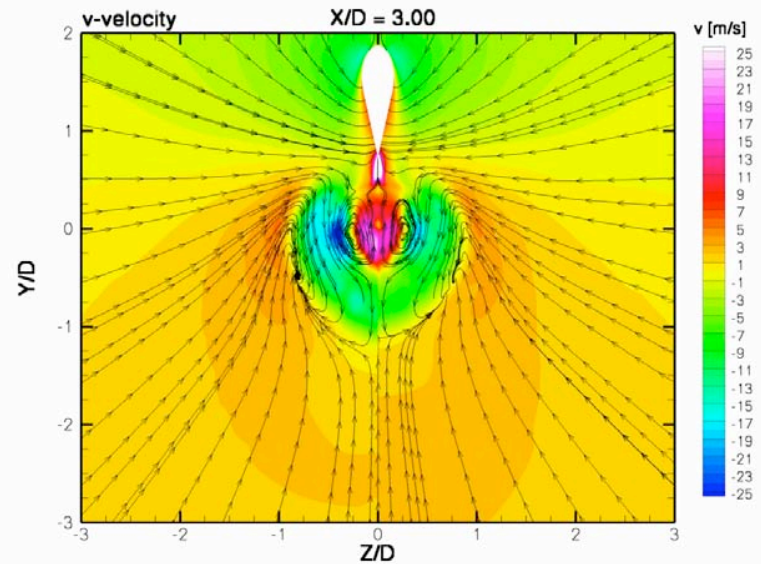

(b) $x / D=3$ : Reference Chevron (RR) left, PAA Chevrons (RT) right

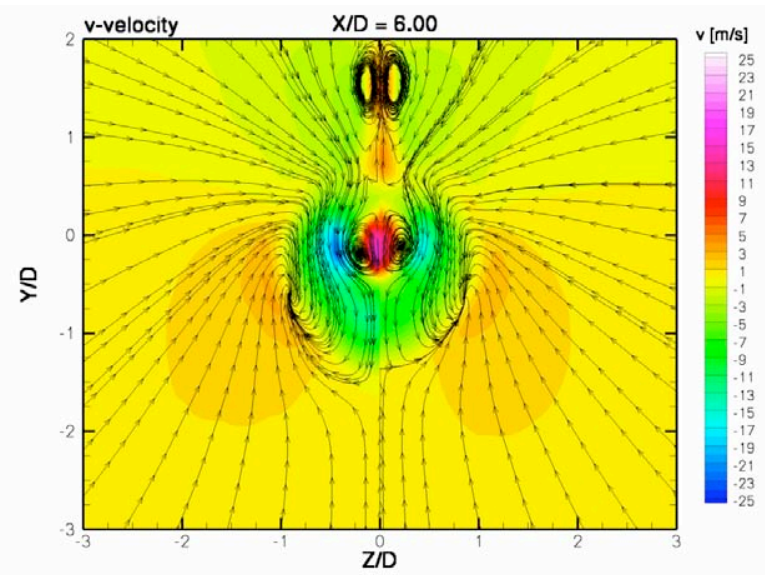

(d) $x / D=6$ : Reference Chevron (RR) left, PAA Chevrons (RT) right

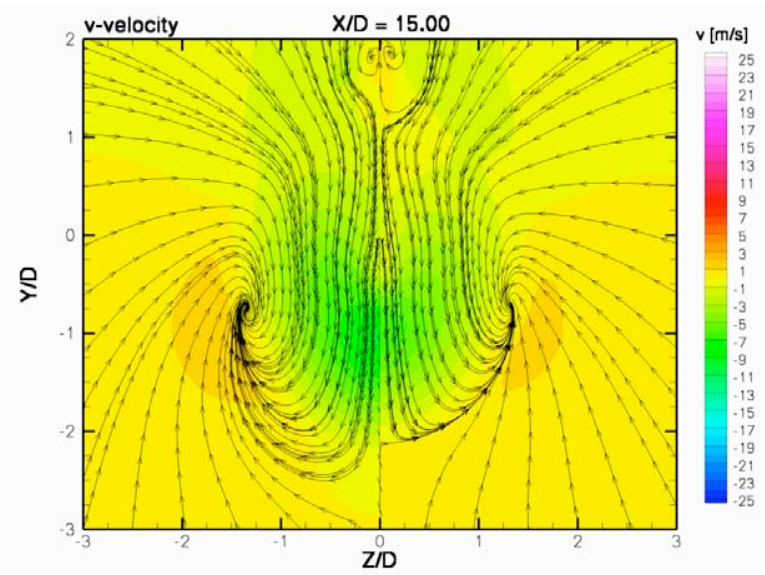

(f) $x / D=15$ : Reference Chevron (RR) left, PAA Chevrons (RT) right

Figure 14. Vertical velocity component, $v[\mathbf{m} / \mathbf{s}]$ with crossflow streamlines at $x / D=3,6,15$ 


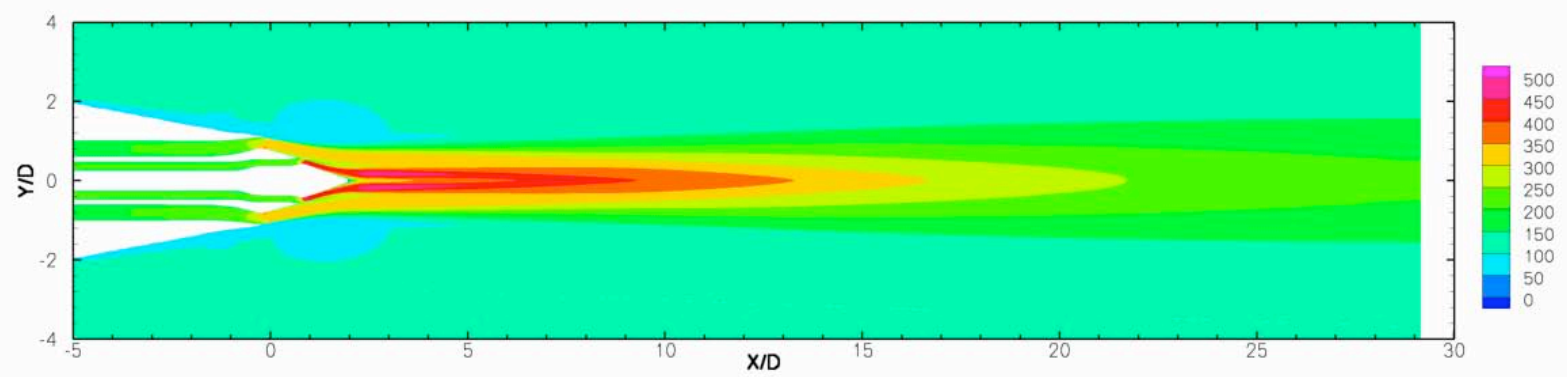

(a) Axisymmetric

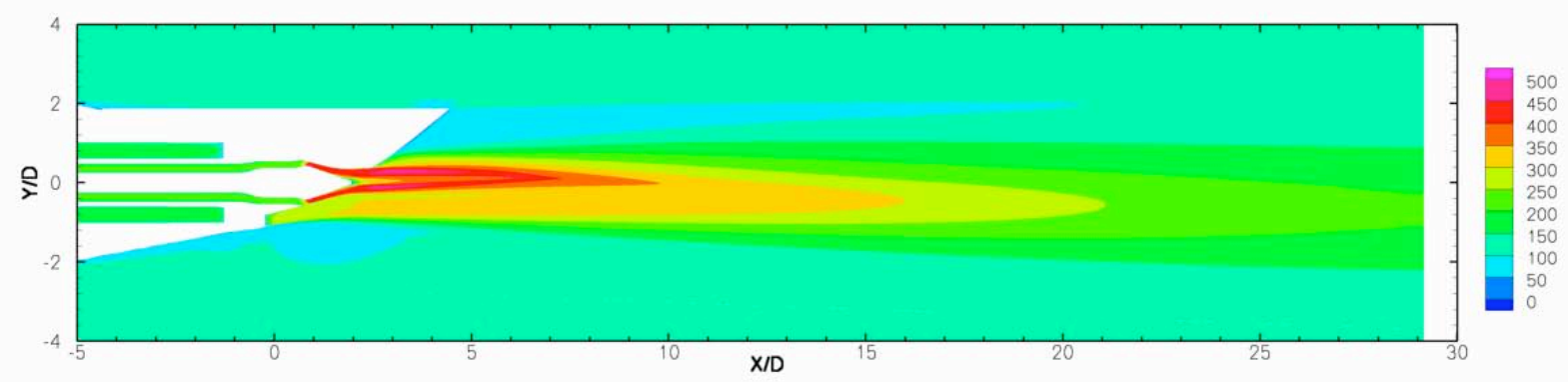

(b) Baseline (bb)

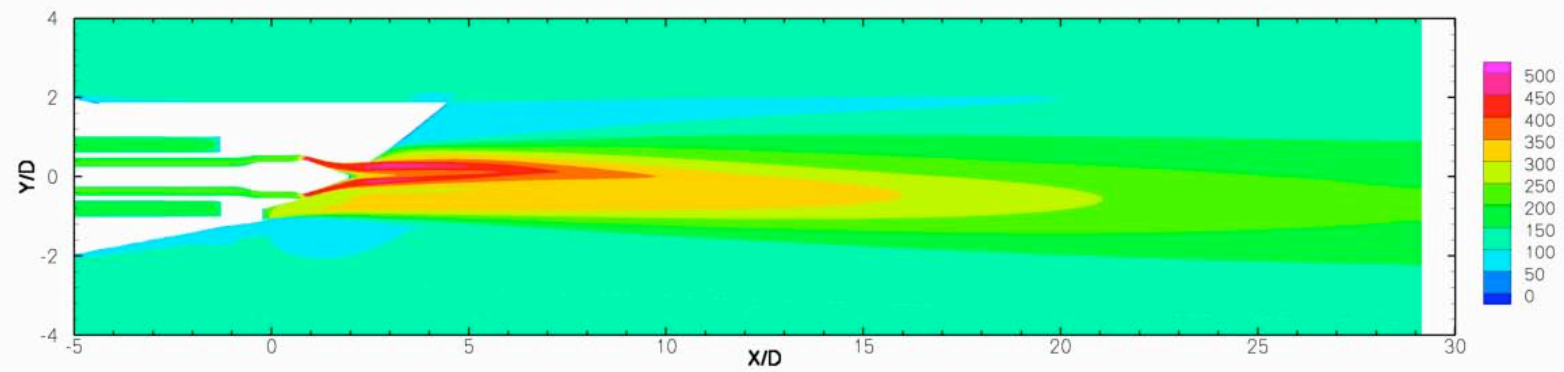

(c) Reference Chevron (RR)

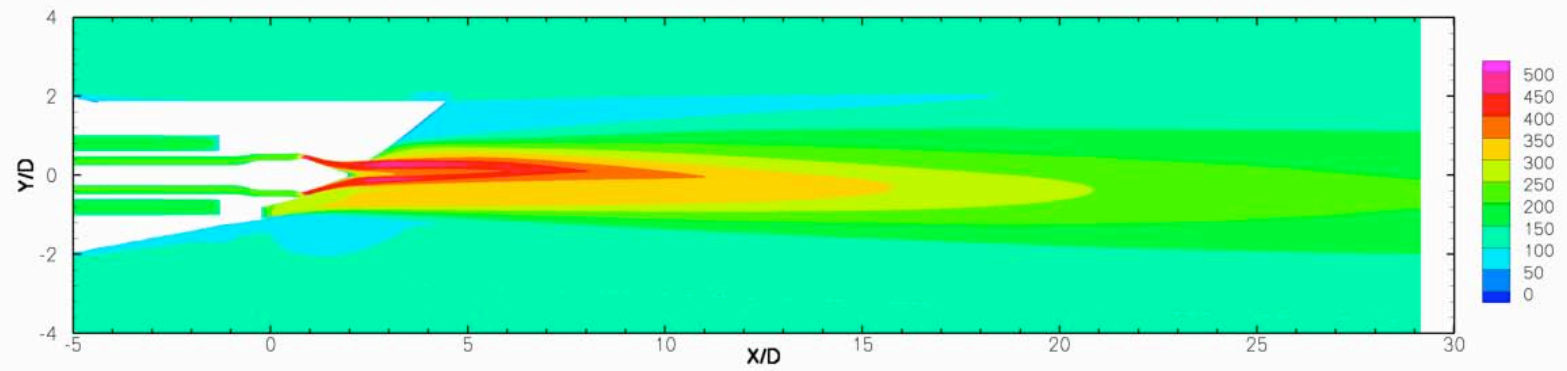

(d) PAA Chevrons (RT)

Figure 15. Axial velocity component, $u[\mathrm{~m} / \mathrm{s}]$ on symmetry planes. 


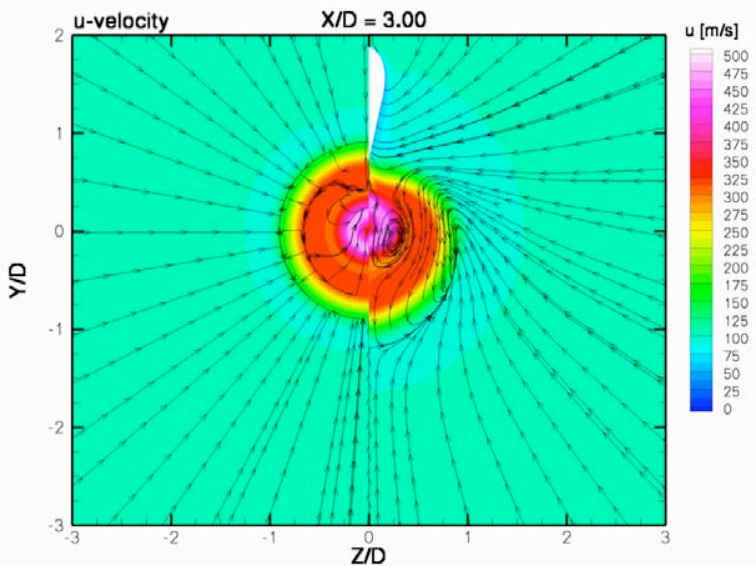

(a) $x / D=3$ : Axisymmetric left, Baseline (bb) right

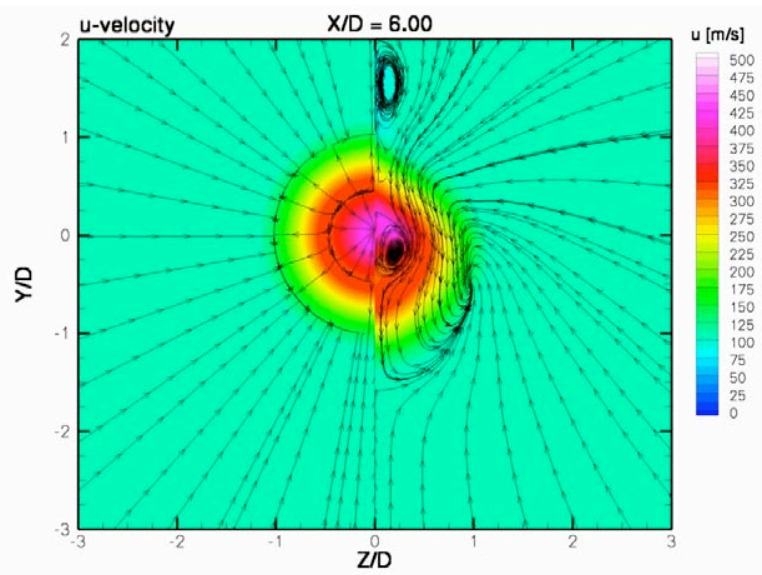

(c) $x / D=6$ : Axisymmetric left, Baseline (bb) right

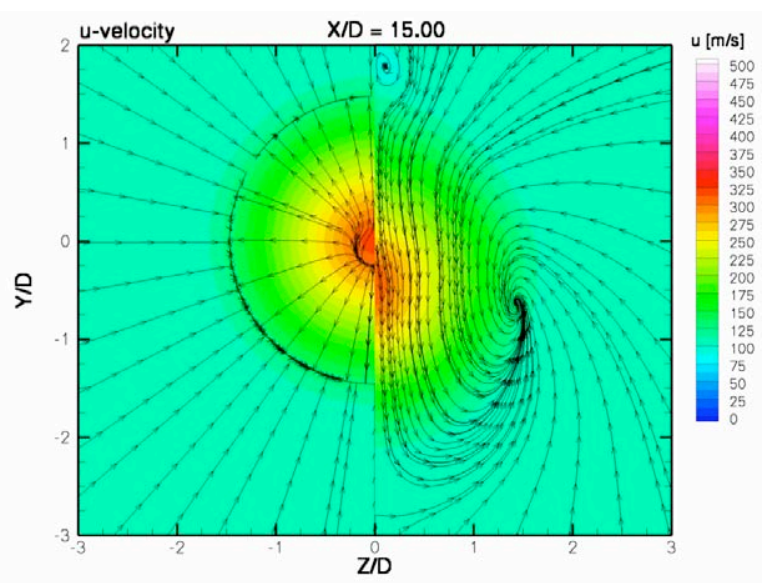

(e) $x / D=15$ : Axisymmetric left, Baseline (bb) right

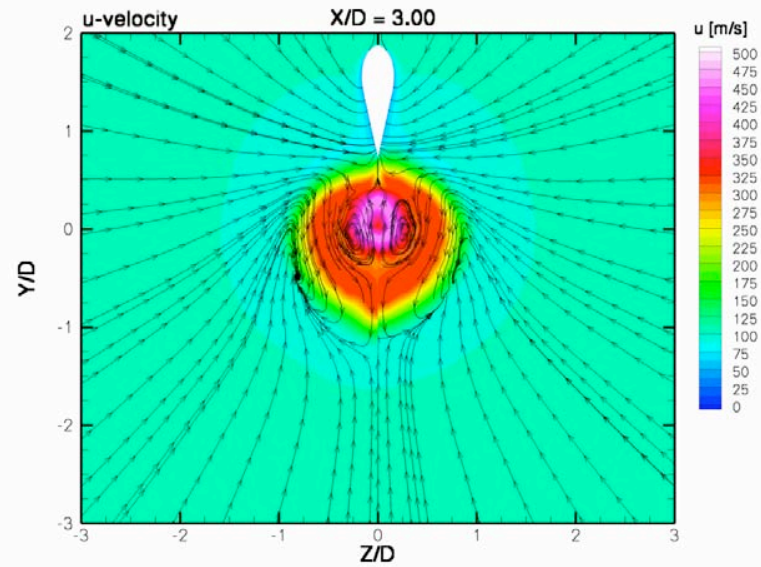

(b) $x / D=3$ : Reference Chevron (RR) left, PAA Chevrons (RT) right

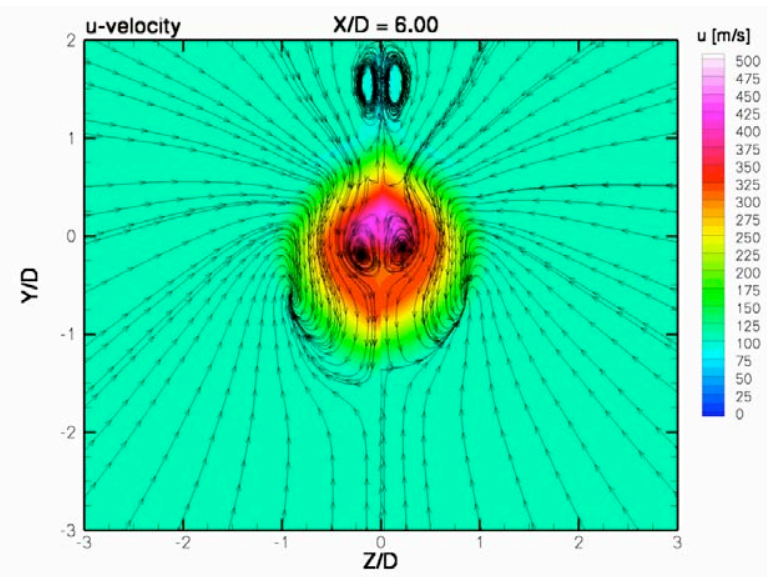

(d) $x / D=6$ : Reference Chevron (RR) left, PAA Chevrons (RT) right

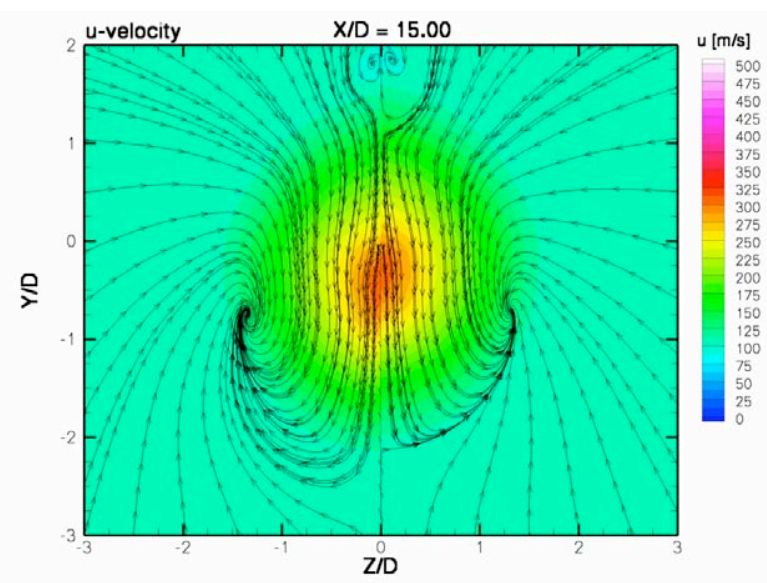

(f) $x / D=15$ : Reference Chevron (RR) left, PAA Chevrons (RT) right

Figure 16. Axial velocity component, $u[\mathbf{m} / \mathbf{s}]$ with crossflow streamlines at $x / D=3,6,15$ 


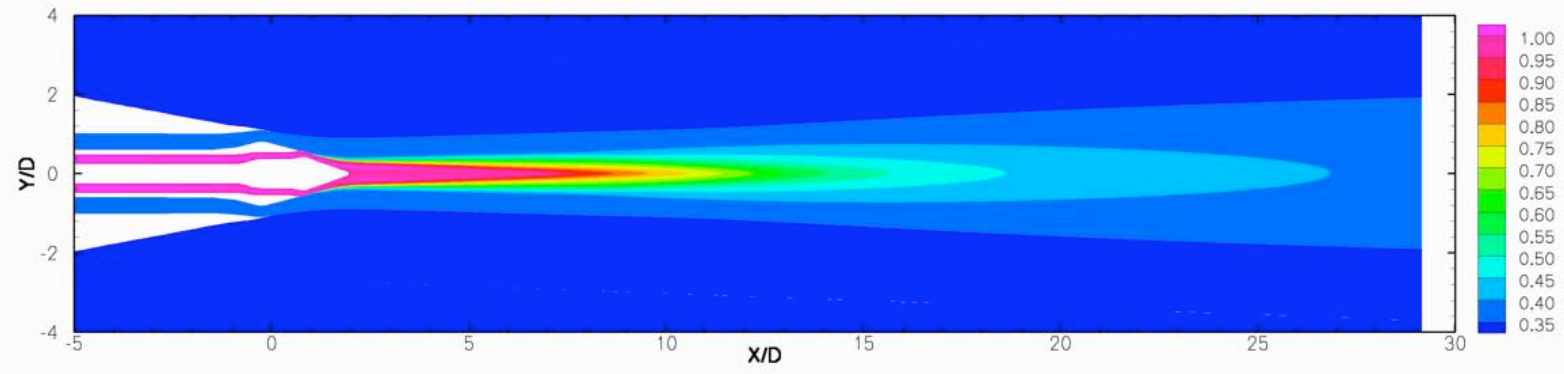

(a) Axisymmetric

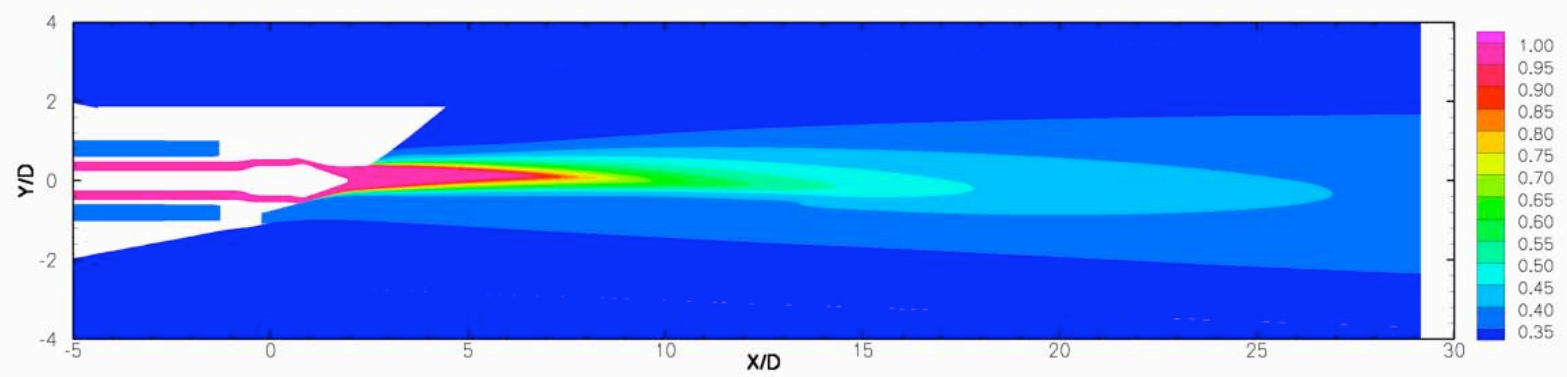

(b) Baseline (bb)

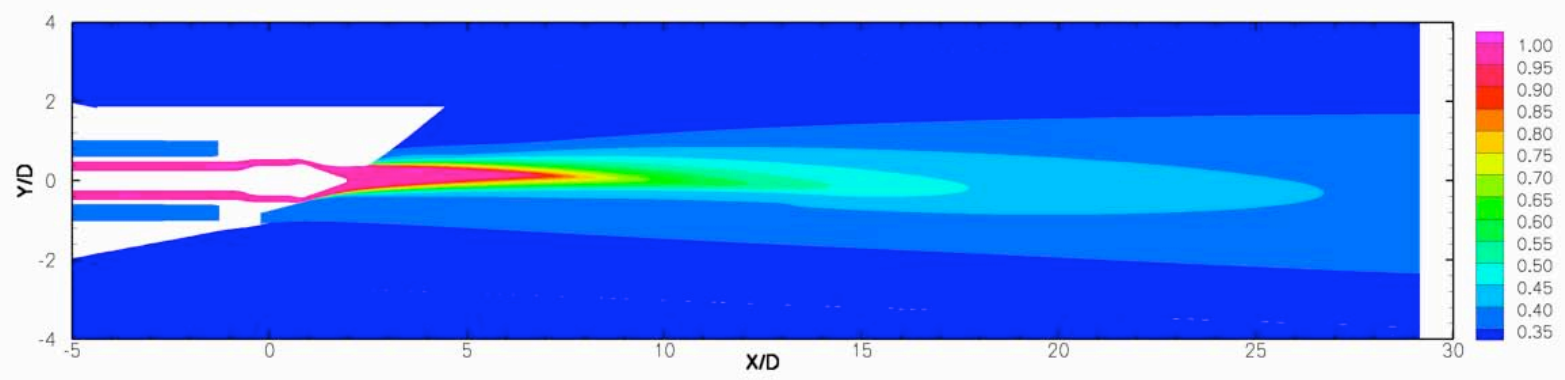

(c) Reference Chevron (RR)

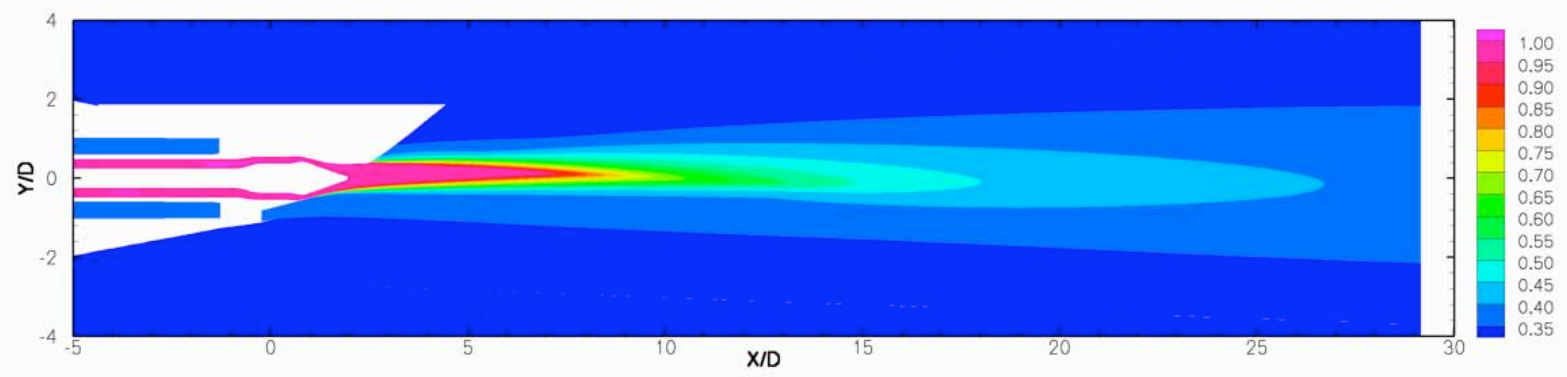

(d) PAA Chevrons (RT)

Figure 17. Total temperature normalized by core stream value on symmetry planes. 


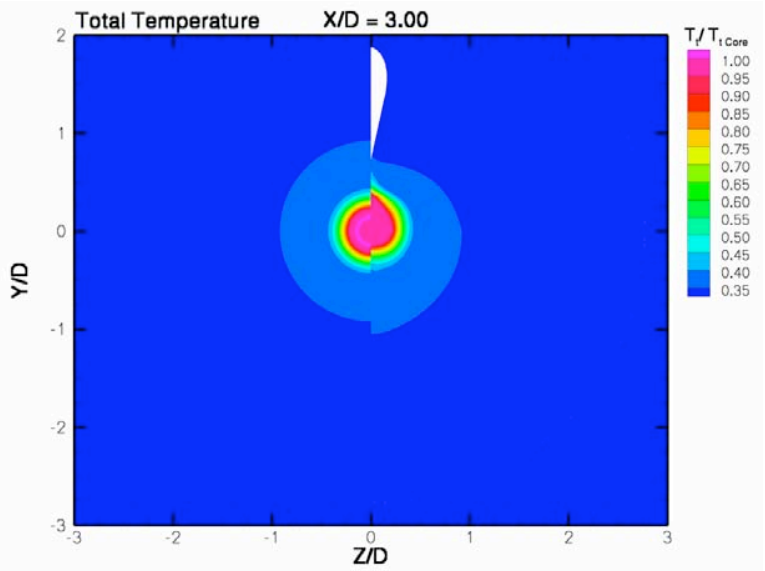

(a) $x / D=3$ : Axisymmetric left, Baseline (bb) right

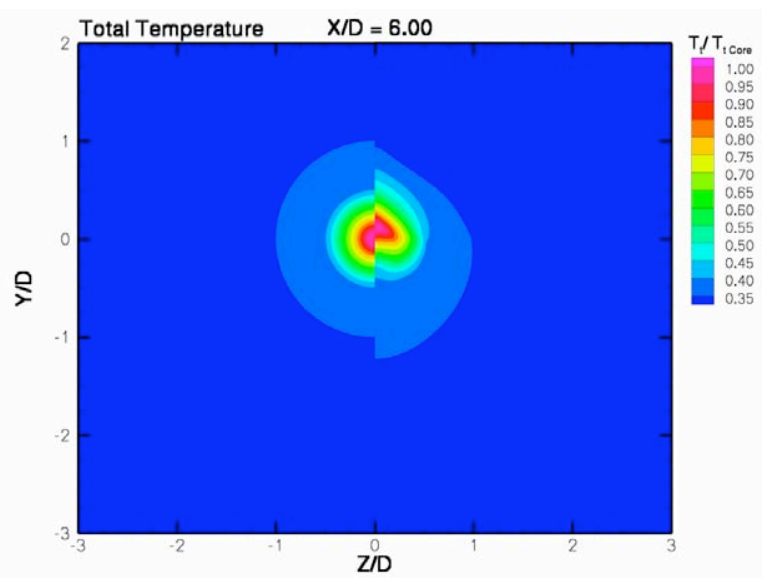

(c) $x / D=6$ : Axisymmetric left, Baseline (bb) right

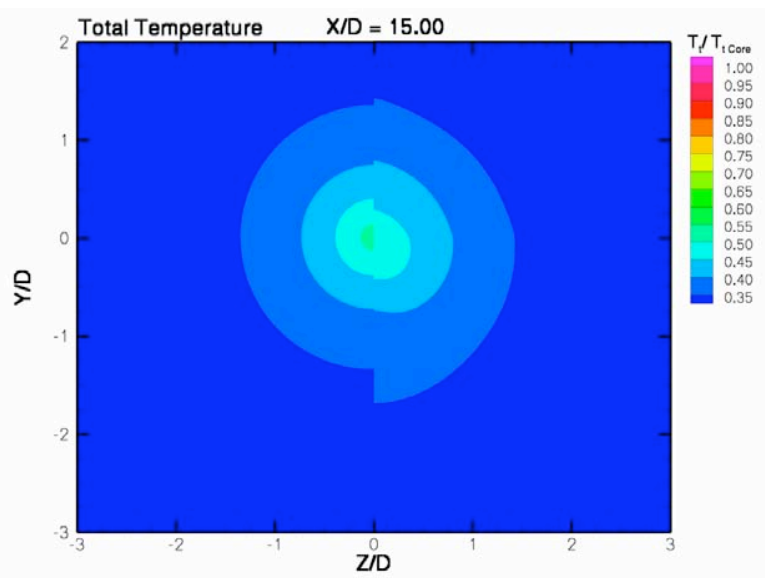

(e) $x / D=15$ : Axisymmetric left, Baseline (bb) right

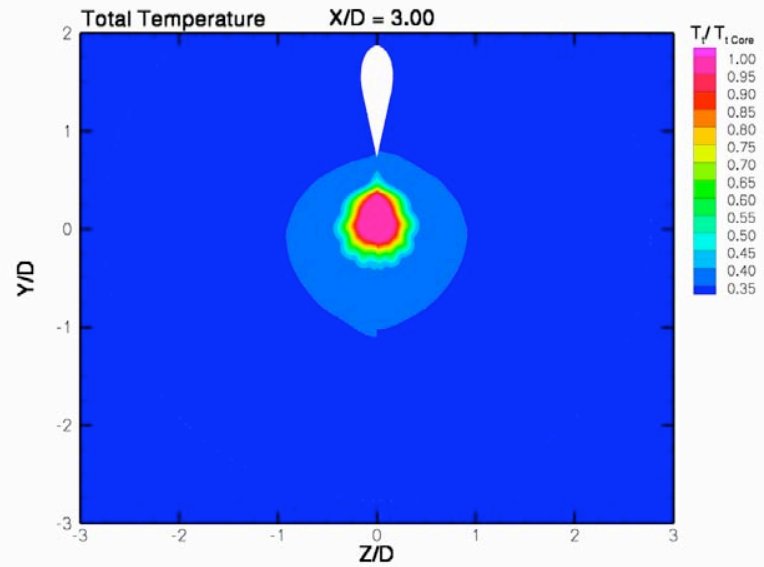

(b) $x / D=3$ : Reference Chevron (RR) left, PAA Chevrons (RT) right

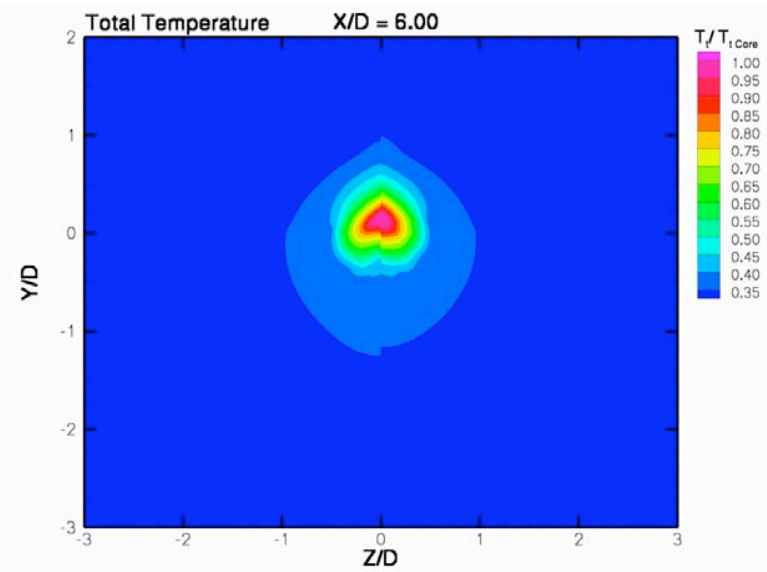

(d) $x / D=6$ : Reference Chevron (RR) left, PAA Chevrons (RT) right

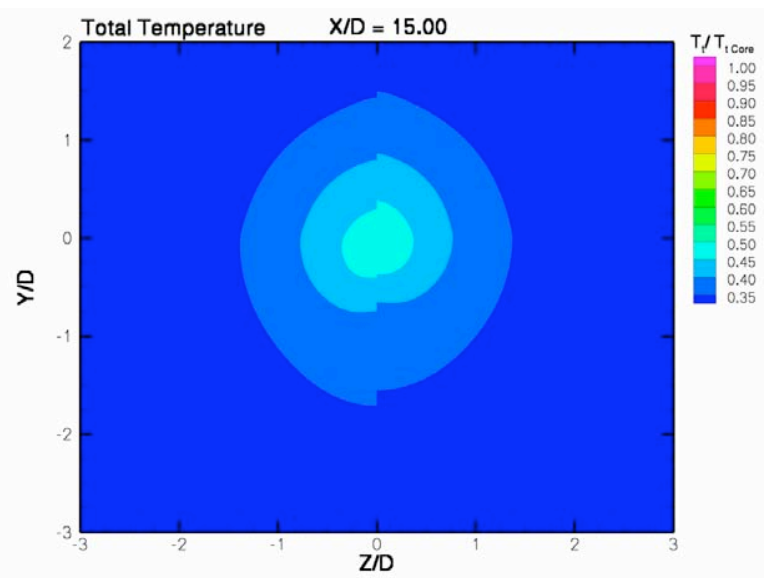

(f) $x / D=15$ : Reference Chevron (RR) left, PAA Chevrons (RT) right

Figure 18. Total temperature normalized by core stream value with crossflow streamlines at $x / D=3,6,15$ 


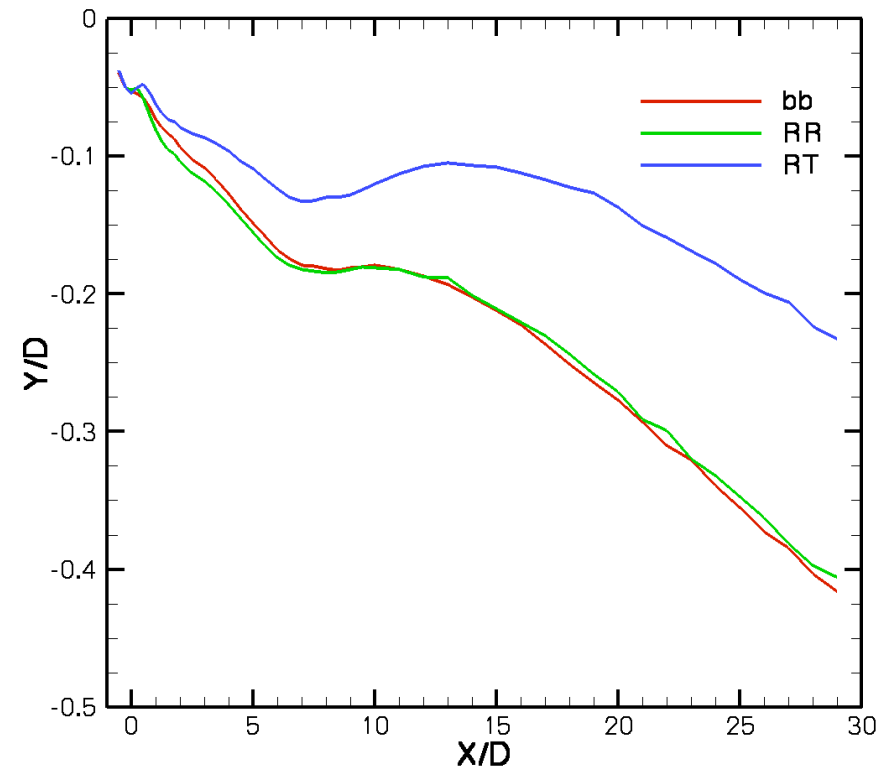

Figure 19. Total temperature centroid at each axial station for $T_{t} \geq 1.01$ Fan $T_{t}$. 